MARTIN FELDSTEIN

Harvard University

ALAN AUERBACH

Harvard University

\title{
Inventory Behavior in Durable-Goods Manufacturing: The Target-Adjustment Model
}

THE RECENT problems of inflation and of a seemingly permanent high rate of unemployment have caused a virtual neglect of research on cyclical fluctuations in demand. Yet even a cursory review of the past twenty years uncovers a familiar pattern of repeated expansion and contraction of industrial production with concomitant changes in employment, capacity utilization, profits, and the like.

Inventory fluctuations have long been recognized as the major endogenous force in American business cycles. Rarely does a study of inventory behavior fail to note that some 75 percent of the cyclical downturn in gross national product from peak to trough can be accounted for by the reduction of business inventories. A decade before Metzler's illuminating analysis of the inventory accelerator process and Abramovitz's fundamental

Note: The authors are grateful to the National Science Foundation for financial support and to Data Resources, Inc., for access to their data and facilities. We have benefited from discussions with Shelby W. Herman of the U.S. Department of Commerce, Bureau of Economic Analysis, about the basic inventory data and the method of calculating constant-dollar inventories from available book-value data. 
empirical analysis of inventory behavior, Keynes was already emphasizing the part played by inventory fluctuations in the minor cycles within the major fluctuations in fixed investment. ${ }^{1}$

In this paper we focus on the behavior of inventories in durables-manufacturing industries, the most volatile component of business inventories. ${ }^{2}$ We have developed new data on the real value both of finished-goods inventories and of the inventories of purchased materials and goods in process that are consistent with the recent revisions of the national income and product accounts. Separate analyses of these two major inventory components are presented for the period from 1959 through the beginning of $1976 .^{3}$

Most of the recent econometric research on the behavior of business inventories builds on the theoretical foundations of optimal production and inventory investment developed by Holt, Modigliani, Muth, and Simon. ${ }^{4}$ The most explicit of these are the studies by Belsley, Childs, and Hay. ${ }^{5}$ The basic stock-adjustment framework used by Lovell and his collaborators ${ }^{6}$

1. See Lloyd A. Metzler, "The Nature and Stability of Inventory Cycles," Review of Economic Statistics, vol. 23 (August 1941), pp. 113-29; Moses Abramovitz, Inventories and Business Cycles (National Bureau of Economic Research, 1950); and John Maynard Keynes, The General Theory of Employment, Interest and Money (Harcourt, Brace, 1936).

2. Inventories in durable-goods manufacturing industries average 27 percent of total business inventories during the period since 1959 . The mean absolute quarterly change in durables inventory investment was $\$ 516$ million, or more than 45 percent of the corresponding change of $\$ 1,126$ million in total business inventory investment.

3. The analysis begins as recently as 1959 because Department of Commerce data on constant-dollar inventories for durable-goods manufacturing are available only since 1958:4.

4. Charles C. Holt, Franco Modigliani, John F. Muth, and Herbert A. Simon, Planning Production, Inventories, and Work Force (Prentice-Hall, 1960). For alternative expositions of this theory with special reference to optimal inventory investment, see Charles C. Holt and Franco Modigliani, "Firm Cost Structures and the Dynamic Responses of Inventories, Production, Work Force, and Orders to Sales Fluctuations," in Inventory Fluctuations and Economic Stabilization, pt. 2, Prepared for the Joint Economic Committee, 87:1 (Government Printing Office, 1961), and David A. Belsley, Industry Production Behavior: The Order-Stock Distinction (Amsterdam: North-Holland, 1969). See also H. Theil, Optimal Decision Rules for Government and Industry (Amsterdam: NorthHolland, 1964).

5. See Belsley, Industry Production Behavior; Gerald L. Childs, Unfilled Orders and Inventories (Amsterdam: Nnrth-Holland, 1967); and George A. Hay, "Adjustment Costs and the Flexible Accelerator," Quarterly Journal of Economics, vol. 84 (February 1970), pp. 140-43.

6. Michael Lovell, "Manufacturers' Inventories, Sales Expectations, and the Acceleration Principle," Econometrica, vol. 29 (July 1961), pp. 293-314; Lovell, "Factors Determining Manufacturing Inventory Investment," in Inventory Fluctuations and Eco- 
can be regarded as a simplified form of the full optimal-inventory model. ${ }^{7}$ These econometric specifications are based essentially on the theory of optimal inventories of finished goods. Belsley and Childs recognize this and limit their studies to the analysis of finished goods. Lovell and Trivedi report separate results for inventories of materials and goods in process, but these are based on less well-developed theoretical foundations. ${ }^{8}$

In reading and reviewing these studies we were struck, as others have been, by the sharp conflict between the estimated parameter values and the underlying model of a lagged adjustment of actual inventories to the current optimal level of inventories. ${ }^{9}$ This is true both of elaborate models that try to capture some of the full complexity of the motivating theory of optimal inventory behavior (for example, the studies of Belsley, Childs, and Hay, all cited earlier) and of the simpler stock-adjustment specifications (for example, the work of Lovell and of Bosworth). Because the theory has been more fully articulated for finished-goods inventories, the conflict has been more obvious in studies of those stocks than in the research on inventories of materials and goods in process.

This conflict between the parameter values and the underlying theory is not resolved by adopting more elaborate sets of variables or more sophisticated methods of statistical estimation. We have concluded that the tradi-

nomic Stabilization, pt. 2; Lovell, "Determinants of Inventory Investment," in National Bureau of Economic Research, Conference on Research in Income and Wealth, Models of Income Determination (Princeton University Press for the National Bureau of Economic Research, 1964); Paul G. Darling and Michael C. Lovell, "Factors Influencing Investment in Inventories," in James S. Duesenberry and others, eds., The Brookings Quarterly Econometric Model of the United States (Rand-McNally, 1965); Albert A. Hirsch and Michael C. Lovell, Sales Anticipations and Inventory Behavior (Wiley, 1969); and Paul Darling and Michael C. Lovell, "Inventories, Production Smoothing, and the Flexible Accelerator," Quarterly Journal of Economics, vol. 85 (May 1971), pp. 357-62.

7. See the discussion below and in Darling and Lovell, "Factors Influencing Investment." Barry Bosworth's study, "Analyzing Inventory Investment," BPEA, 2:1970, pp. 207-27, also adopts this general framework. A useful critical survey of recent econometric research on inventory investment is presented by J. C. R. Rowley and P. K. Trivedi, Econometrics of Investment (Wiley, 1975), chaps. 2, 6. Earlier studies are reviewed by Robert Eisner and Robert H. Strotz in "Determinants of Business Investment," in Daniel B. Suits and others, Impacts of Monetary Policy, Prepared for the Commission on Money and Credit (Prentice-Hall, 1963).

8. P. K. Trivedi, "Time Series Versus Structural Models: A Case Study of Canadian Manufacturing Inventory Behavior," International Economic Review, vol. 16 (October 1975), pp. 587-608.

9. The precise nature of this conflict between the apparent slowness of stock adjustment and the rapidity of error correction is discussed below. 
tional model of lagged inventory adjustment is an inappropriate theoretical specification. This paper presents an alternative model of inventory investment based on the assumption that full adjustment is, at the least, nearly completed within each quarterly period. The preliminary tests of this new "target-adjustment model" are encouraging.

We believe that it is important to deal separately with inventories of finished goods and of materials and goods in process. Doing so should improve understanding of total inventory fluctuations, especially since the two components of inventory investment are essentially uncorrelated $(r=0.19)$. Separate treatment provides an opportunity to develop a more complete econometric specification within which to compare the traditional lagged stock-adjustment model with the new target-adjustment model. Since materials and goods in process account for more than two-thirds of the variation in inventory investment, ${ }^{10}$ it is also appropriate to compensate for the much greater attention that has previously been focused on finished-goods inventories.

This study should be viewed as a first step in analyzing the contribution of inventory behavior to macroeconomic stability. Previous studies are inappropriate for such an analysis because the published parameter estimates conflict with the stock-adjustment model on which the estimating equations themselves are based. Moreover, the very slow speed of adjustment implied by the estimated stock-adjustment model seems incompatible with both prior expectations and the basic characteristics of the data presented below. Because the target-adjustment model eliminates these inconsistencies and incompatibilities, the resulting parameter estimates can be used more readily to analyze the macroeconomic role of inventory behavior.

We begin our analysis by examining some basic measures of inventory investment and fluctuations. The next section investigates the quality of sales forecasts, an important issue in the analysis of finished-goods inventories. Next we turn to the theory and estimation of alternative models of finished-goods inventories. A parallel analysis for inventories of materials and goods in process is presented in the following section. The fifth section uses the parameter estimates to examine the experience of quarterly inventory investment in 1974 and 1975. A brief concluding section points to directions for future research. A more detailed discussion of estimates

10. The statement applies to durable-goods manufacturing. Since all of our analysis deals with this sector we omit this phrase hereafter. 
based on the optimization model of Holt, Modigliani, Muth, and Simon appears in an appendix.

\section{Five Basic Characteristics of Inventory Investment}

All of our analysis deals with seasonally adjusted quarterly data on the inventories of establishments that manufacture durable goods. Because the Department of Commerce has not yet developed data on real inventories by stage of fabrication, we have derived new constant-dollar series for finished goods and for materials and goods in process. The sum of these two series is the value given in the official national income accounts of durables-manufacturing inventories in 1972 dollars. For finished-goods inventories, we have followed the basic official procedure of converting seasonally adjusted monthly current book-value inventories to the corresponding constant-dollar values using monthly price series and information on both the LIFO-FIFO composition of inventories and the monthly age profile of goods in inventory. ${ }^{11}$ The corresponding value of inventories of materials and goods in process is obtained by subtracting real finishedgoods inventories from the value of total durable-goods manufacturing inventories reported in the national income accounts. ${ }^{12}$ Our inventory series are created in this way from 1958:4 to 1976:1 - that is, the entire period for which official data are available for total inventories of durable-goods manufacturing in constant 1972 dollars. We are not unaware of the many problems with the available inventory statistics.

We have singled out five basic characteristics of the inventory data for evaluating alternative models and parameter values.

11. The procedure is described in detail in appendix B; the resulting series are available from the authors. For a more detailed discussion of the official method, see Shelby W. Herman, Gerald F. Donahoe, and John C. Hinrichs, "Manufacturing and Trade Inventories and Sales in Constant Dollars, 1959 to First Quarter 1976," Survey of Current Business, vol. 56 (May 1976), pp. 11-24. Note that we derive the adjusted series from aggregate durables-manufacturing data while the Department of Commerce adjusts industry data before aggregating.

12. We derive constant-dollar finished-goods inventories and subtract from the total to get inventories of materials and goods in process rather than the other way around because it is much easier to deflate finished-goods inventories. After splitting finishedgoods inventories into LIFO and FIFO inventories, we can deflate and reflate with the price index for shipments of manufactured durable goods. No such single price index would be as suitable for purchased materials and goods in process. 
The first, of particular importance, is that even major changes in inventories represent the outputs and inputs of only very short time periods.

An examination of finished-goods inventories reveals the importance of this point. During the seventeen years ending in March 1976, these inventories averaged 18.6 percent of quarterly sales. ${ }^{13}$ But the relative size of the stock is less important than the relative size of the changes in the stockthat is, of net investment in finished-goods inventories. During the same seventeen-year period, the deepest drop in these stocks was $\$ 897$ million, from the end of 1975:1 to the end of 1976:1. Quarterly shipments averaged $\$ 93.3$ billion during this period, implying daily production of about $\$ 1.5$ billion. The entire year's fall in the stock of finished-goods inventories was thus equal to less than one day's production! The largest one-year increase in finished-goods inventories was a $\$ 2.0$ billion rise from the end of 1966:2 to the end of $1967: 2$. Since quarterly shipments averaged $\$ 91.4$ billion during this period, the largest single year's increase in the stock of finishedgoods inventories was equal to less than two days' production!14

Although inventories of purchased materials and goods in process are more volatile, the basic conclusion is qualitatively similar. ${ }^{15}$ The deepest drop in these inventories, from the end of 1974:4 to the end of 1976:1, was $\$ 4.5$ billion. If the entire reduction had been a change in goods-in-process inventories it could be stated as equivalent to less than three days of production during the fifteen-month period. However, a large part of the reduction was in purchased materials and should be compared to the rate of inflow of such materials. During the relevant five quarters, the average quarterly use of purchased materials was $\$ 57.2$ billion, ${ }^{16}$ implying an aver-

13. Note that by definition sales and shipments are identically equal. Note also that both inventories and sales are, as always in this paper, in constant 1972 dollars.

14. Of course, the change in inventory will be larger relative to production for some individual firms or industries. The figures for a single day's and two days' production are derived by comparing the change in inventories of goods produced to stock with the flow of both production to order and production to stock. But the proposition that the inventory change represents a very short period of production is likely to be true in general even at a microeconomic level.

Recall that the inventory decrease discussed above was the largest total fall irrespective of the interval. Expansions last much longer. During the longest such expansion, which lasted ten years-from 1961:1 to 1971:1-inventories rose $\$ 7.86$ billion; that was equivalent to less than seven days of production.

15. There is, moreover, no problem here of comparing production-to-stock inventories with total production. Inventories of materials and goods in process relate to all firms.

16. The use of purchased materials in each quarter was approximated as the difference between the value of completed production and the value added in production. Quarterly 
age daily use of slightly less than $\$ 1$ billion. If it were purchased materials alone, the entire fifteen-month fall could be achieved by eliminating less than five days' deliveries. Given these short periods of correction for either component taken by itself, the actual mix of purchased materials and goods in process is irrelevant. Even the dramatic 20 percent rise in inventories of materials and goods in process between 1972:1 and 1974:4 amounted to only about three days of production per year or four days of materials purchases per year.

The second basic characteristic of inventories revealed by the data is that investment in inventories of materials and goods in process is about three times as large and three times as volatile as investment in finished-goods inventories.

To simplify the discussion, let $I F G_{t}$ be the stock of finished-goods inventories at the end of period $t$, and $I M G_{t}$ inventories of materials and goods in process. Investment in finished-goods inventories will be denoted $D I F G_{t}=I F G_{t}-I F G_{t-1}$ and the change in such investment will be written $D^{2} I F G_{t}=D I F G_{t}-D I F G_{t-1}$. The time subscript will be omitted when it is not needed for clarity. All variables are seasonally adjusted.

From 1959:1 to 1976:1, the average value of investment in materials and goods in process $(D I M G)$ was $\$ 436$ million per quarter, while the average of $D I F G$ was only $\$ 127$ million. The corresponding standard deviations provide one simple measure of the quarterly volatility of inventory investment: $\$ 783$ million for DIMG and $\$ 243$ million for DIFG. An alternative measure of volatility, the mean absolute inventory change, tells the same story: $\$ 754$ million for $D I M G$ and $\$ 219$ million for $D I F G$. This volatility ratio of about three to one is confirmed by comparing the quarterly absolute-value changes in inventory investment, denoted $D^{2}: D^{2} I M G$ had a mean of $\$ 479$ million while $D^{2} I F G$ had a mean of only $\$ 174$ million.

Third, the two types of inventory investment are essentially uncorrelated. There is a common tendency to discuss variations in the ratios of total inventory to sales and to analyze changes in total inventories without regard to stage of fabrication. This is unfortunate since the correlation of the two basic types of inventory investment is only 0.19 , while that for changes in inventory investment, $D^{2} I M G$ and $D^{2} I F G$, is only -0.025 . Even with

value added for durables manufacturing is actually an interpolation of the annual series using the appropriate index of industrial production. Comparing the $\$ 57.2$ billion of purchased materials with the corresponding $\$ 92.8$ billion of completions indicates that the ratio of value added to completions is about one-third, a quite plausible estimate for durables manufacturing. 
Table 1. Volatility of Investment in Inventories in Durable-Goods

Manufacturing and of Other Components of GNP Change,

Quarterly, 1959:2-1976:1

Millions of 1972 dollars

\begin{tabular}{lcc}
\hline \multicolumn{1}{c}{ Component of $G N P^{\mathrm{a}}$} & $\begin{array}{c}\text { Mean } \\
\text { absolute } \\
\text { change }\end{array}$ & $\begin{array}{c}\text { Standard } \\
\text { deviation }\end{array}$ \\
\hline $\begin{array}{l}\text { Change in investment in inventories of materials and } \\
\text { goods in process, durable-goods manufacturing, }\end{array}$ & & \\
$\quad D^{2} I M G$ & 479 & 597 \\
Change in investment in finished-goods inventories, & & \\
$\quad$ durable-goods manufacturing, $D^{2} I F G$ & 174 & 227 \\
$\quad$ Total, $D^{2}(I M G+I F G)$ & 516 & 627 \\
Change in investment in total business inventories, & & \\
$\quad D^{2}(I B U S)$ & 1,126 & 1,660 \\
$\quad$ Total fixed investment, $D(I F I X)$ & 774 & 950 \\
Change in gross national product, $D(G N P)$ & 2,840 & 2,756 \\
$D(G N P-D I B U S)$ & 2,359 & 2,094 \\
\hline
\end{tabular}

Source: See appendix $B$.

a. $D$ indicates investment in the component, $D^{2}$ indicates change in such investment, and the symbol without $D$ signifies the stock of the component.

annual data, the correlation is a low 0.29 . With quarterly data, the regression of $D I M G_{t}$ on the concurrent value of $D I F G_{t}$ and three separate lagged values $\left(D I F G_{t-1}, D I F G_{t-2}\right.$, and $\left.D I F G_{t-3}\right)$ has a statistically insignificant $\bar{R}^{2}$ of 0.13 .

Fourth, changes in inventory investment in durables manufacturing are large in relation to total fluctuations in GNP.

Although inventory investment for durable-goods manufacturing has accounted for an average of only 0.23 percent of gross national product during our sample period, the variation in inventory investment is surprisingly large relative to the changes in GNP.

Table 1 compares the standard deviation of quarterly changes and the mean absolute quarterly change of GNP net of total business inventory investment (GNP-DIBUS) with the corresponding measures of volatility for inventory investment and fixed investment. Note in particular that the quarterly changes in inventory investment in durables manufacturing represent by themselves about one-fourth of the total noninventory variation in GNP or, viewed another way, are more than one hundred times as important as the share of such inventory investment in GNP. Fluctuations in total business inventories are nearly half as large as all other sources of variation in GNP combined. 
The fifth and last basic characteristic of inventories disclosed by the data is that quarterly variations in the accumulation of finished-goods inventories are stabilizing while quarterly variations in the inventories of materials and goods in process are destabilizing.

It is well known that the accumulation of finished-goods inventories rises when the remainder of gross national product falls. In fact, during the seventeen-year period from 1959:2 to 1976:1 the correlation between changes in investment in finished goods $\left(D^{2} I F G\right)$ and changes in GNP net of investment in finished goods-that is, $D(G N P-D I F G)$-was -0.091 . A negative correlation is, of course, necessary but not sufficient to make the variation in finished-goods inventories reduce the overall variation in GNP; it must be powerful enough to offset the direct contribution of variation in $D I F G$. We have found that, at least during our seventeen-year sample period, the negative correlation was strong enough to make variations in the accumulation of finished-goods inventories reduce slightly the variance of GNP changes. ${ }^{17}$ The standard deviation of $D^{2} I F G$ is $\$ 227$ million; because of its negative correlation with the other components of the change in GNP, the variability of $D^{2} I F G$ reduces the standard deviation of $D G N P$ by $\$ 11$ million. This is 5 percent of the standard deviation of $D^{2} I F G$.

In contrast, changes in the accumulation of materials and goods in process in manufacturing are positively correlated with the other components of the change in GNP. During the sample period, the correlation was 0.05 . As a result, the $\$ 597$ million standard deviation of $D^{2} I M G$ actually adds $\$ 102$ million to the standard deviation of $D G N P$.

\section{The Poor Quality of Sales Expectations}

Important evidence for understanding the process of investment in finished-goods inventories is the quality of firms' sales expectations. In brief, if firms are surprised by sales, the change in finished-goods inventories will reflect unanticipated sales (or a shortfall of sales) as well as

17. What is at issue here follows from the fact that the variance of a sum is the sum of the variances plus twice the covariance. Quarterly changes in GNP can be divided into $D^{2} I F G$ and the remainder, $D G N P-D^{2} I F G$. The variance of $D G N P$ is increased by the variability of $D^{2} I F G$ unless the covariance is negative and large enough to offset the direct contribution of the variance of $D^{2} I F G$. We have found that this condition is satisfied. 
intended inventory accumulation. In contrast, if sales expectations are perfect, all of the observed change in finished-goods inventories will be intended. Knowing the size of the forecast error also permits estimating the speed with which firms can make adjustments to avoid unintended accumulation.

Although we shall compare the expected sales changes with the naive forecast of no change in sales, the important issue is not the actual quality of sales forecasting per se but the size of the typical forecast errors relative to production and to inventory adjustment. Three basic findings emerge from our empirical analysis:

(1) The sales expectations are poor even when judged by the standard of the most naive "no change" forecast.

(2) The sales-forecast error is nevertheless small in relation to the quarterly rate of production, providing adequate opportunity for nearly complete adjustment to eliminate this source of unintended inventory accumulation.

(3) The forecast error is large in comparison to even major inventory changes, indicating that the general adjustment of inventories to target levels should be even more complete than the adjustment to offset unanticipated changes in sales.

Our conclusions are based on an analysis of the official Department of Commerce survey of the sales expected by durables-manufacturing firms..$^{18}$ Comparable data are available on a quarterly basis for the period from 1961:3 through 1976:1. We have analyzed the data in the form of seasonally adjusted constant 1972 dollars, using the same deflation and seasonaladjustment procedure that is used for actual sales. This adjustment makes our results less comparable with earlier research but more relevant for the subsequent analysis in this paper. Since we shall analyze seasonally ad-

18. The published sales expectations cannot be compared to actual sales because the latter, but not the former, have been rebenchmarked. To derive an expected-sales series that is consistent with the most recently benchmarked series of actual sales, we work with the expected percentage changes in sales. These in turn are derived by comparing the published series on expected sales with the concurrently published actual sales before they are rebenchmarked. The basic survey is described in Murray F. Foss, "Manufacturers' Inventory and Sales Expectations," Survey of Current Business, vol. 41 (August 1961), pp. 27-31. The survey began in 1957:3 but the data before 1961:3 are not comparable with later data. See also the discussion of these data in Michael C. Lovell, "Sales Anticipations, Planned Inventory Investment, and Realizations," in Robert Ferber, ed., Determinants of Investment Behavior (Columbia University Press for the National Bureau of Economic Research, 1967). 
justed inventory investment we want to understand the size and implications of the forecast error on a seasonally adjusted basis. ${ }^{19}$

The Department of Commerce surveys two separate sales forecasts at the beginning of each quarter. The first is a forecast of sales during the current quarter, denoted here $S_{t, t}^{e}$, and the second a forecast of sales during the next quarter, $S_{t+1 t}^{e}$. The superscript $e$ denotes expectations, the first subscript denotes the quarter during which that level of sales is expected to occur, and the second subscript refers to the quarter at the beginning of which the forecast is reported to Commerce. To the extent that firms do not continually update their forecasts, the time at which the forecast is made will be earlier than the time at which it is reported. ${ }^{20}$ Actual sales will be written $S_{t}$. Actual and expected sales are stated at quarterly rates (that is, one-fourth of annual sales rates) in billions of 1972 dollars.

Consider first the relation between actual and expected changes in sales shown in equation 1 . (Here and in the following equations the numbers in parentheses are standard errors.)

$$
\begin{aligned}
& S_{t}-S_{t-1}=0.257+0.553\left(S_{t, t}^{e}-S_{t-1}\right) . \\
& \text { (0.303) (0.099) }
\end{aligned}
$$

Sample period $=1961: 4-1976: 1 ; \bar{R}^{2}=0.346 ;$ standard error $=2.252$; Durbin-Watson $=1.324$.

The $\bar{R}^{2}$ value is only 0.346 . The regression coefficient is also small. Although

19. In comparing our results with previous research based on the seasonally unadjusted data, readers should bear in mind that firms are likely to be quite good at forecasting the seasonal component of their sales change while the naive forecast of unchanged sales obviously ignores it. Seasonally unadjusted forecasts are therefore likely to look better in comparison to the naive forecasts than the seasonally adjusted analysis that we present. The first few years of the current data were studied on a more disaggregated basis in Lovell, "Sales Anticipations, Planned Inventory Investment, and Realizations," and in Hirsch and Lovell, "Sales Anticipations and Inventory Behavior." Earlier studies include Robert Ferber, The Railroad Shippers' Forecasts (University of Illinois, 1953); Franco Modigliani and Owen H. Sauerlender, "Economic Expectations and Plans of Firms in Relation to Short-Term Forecasting," in National Bureau of Economic Research, Conference on Research in Income and Wealth, Short-Term Economic Forecasting (Princeton University Press for the National Bureau of Economic Research, 1955); and B. Peter Pashigian, "The Accuracy of the Commerce-S.E.C. Sales Anticipations," Review of Economics and Statistics, vol. 46 (November 1964), pp. 398-405.

20. The forecasts reported in the survey may also differ from the forecasts used by firms for their actual decisions. Sales-forecast data may be a poor measure of firms' beliefs. Although we shall analyze the sales-forecast data as if they represent accurate reporting, none of our basic conclusions or final target-adjustment model estimates rests on these data. 
Table 2. Comparison of Errors from Alternative Sales Forecasts for Durable-Goods Manufacturing, Quarterly, 1961:4-1976:1

\begin{tabular}{|c|c|c|c|}
\hline \multirow[b]{2}{*}{ Sales or forecast } & \multicolumn{2}{|c|}{$\begin{array}{c}\text { Error } \\
\text { (billions of } 1972 \text { dollars) }\end{array}$} & \multirow{2}{*}{$\begin{array}{l}\text { Average } \\
\text { absolute } \\
\text { error } \\
\text { (percent) }\end{array}$} \\
\hline & $\begin{array}{l}\text { Average } \\
\text { absolute }\end{array}$ & $\begin{array}{l}\text { Standard } \\
\text { deviation }\end{array}$ & \\
\hline Actual sales during last quarter, $S_{t-1}$ & 2.10 & 2.79 & 2.3 \\
\hline Forecast of sales during current quarter, $S_{t, t}^{e}$ & 2.01 & 2.61 & 2.1 \\
\hline $\begin{array}{l}\text { Forecast of sales during current quarter made } \\
\text { last quarter, } S_{t, t-1}^{e}\end{array}$ & 3.05 & 3.97 & 3.3 \\
\hline
\end{tabular}

Source: See discussion in text.

a. Standard deviation of the forecast errors.

it is significantly different from zero, it is also very much different from the value of 1.0 required for an unbiased forecast $(t=4.5)$. When the forecasts collected in the previous quarter $\left(S_{t, t-1}^{e}-S_{t-1, t-1}^{e}\right)$ are used, the correlation is substantially worse $-\bar{R}^{2}=0.184$.

The same poor quality of forecast is apparent when the forecast errors are compared with the error implied by the naive forecast of no change $\left(S_{t}^{e}=S_{t-1}\right)$. Table 2 reports alternative measures of the actual magnitudes of the forecast errors. The naive forecast (shown in the first row) entails an average absolute error of $\$ 2.10$ billion of sales per quarter. The corresponding average absolute error of the firms' forecasts reported at the beginning of the quarter was nearly as large (\$2.01 billion per quarter), and the error of the forecast made in the previous quarter was even larger, $\$ 3.05$ billion. Using the standard deviations of the forecast errors (not of their absolute values) gives more weight to large errors but does not alter the ranking of the forecasts; this is shown in the second column. Dividing the absolute forecast error for each quarter by the actual sales for that quarter provides the absolute percentage error; the averages of these, presented in the third column, again indicate that the naive "no change" forecast is about as good as the reported forecasts.

Economists have been interested in the sales-forecast error as a source of unanticipated inventory accumulation at least since the publication in 1941 of Metzler's theoretical study of the inventory cycle. In this important context, the size of the sales-forecast error should be judged by the production time required for its correction; the relative size of the forecast error and of the error generated by a naive-expectation model is really 
irrelevant. The average absolute error of $\$ 2.01$ billion per quarter is equal to about one day's production..$^{21}$ The standard deviation of the corresponding forecast errors (not absolute, of course) is $\$ 2.61$ billion; since the mean error is approximately zero (actually $\$ 0.03$ billion), a forecast error of two standard deviations ( $\$ 5.2$ billion) will indicate the production flow required to correct a very large mistake: approximately four days' worth. Using the forecasts from the previous quarter $\left(S_{t, t-1}^{e}\right)$ increases these estimates by only a day. These figures suggest that forecast errors should not be a source of any substantial undesired quarterly changes in inventories. ${ }^{22}$ Indeed, one possible explanation of the poor quality of the forecasts per se is that this range of error can be corrected easily and with little extra cost.

Although problems arise in comparing the size of the forecast errors with the size of inventory changes, it seems safe to conclude that forecast errors are large in comparison to even major inventory changes. The average absolute quarterly change in finished-goods inventories was only $\$ 0.22$ billion, or less than 11 percent of the corresponding forecast error. More relevant than the average inventory change per single quarter, the largest cumulative inventory decrease was the fall of $\$ 0.9$ billion from 1975:1 to 1976:1 while the largest annual increase was the rise of $\$ 2.0$ billion from 1966:2 to $1967: 2$. This inventory change applies (by definition) only to goods produced to stock while the sales-forecast error applies to both production to stock and production to order. But even a generous allowance for this difference could not make the quarterly inventory changes look large in relation to the errors in reported sales forecasts. This observation

21. Sales averaged $\$ 90$ billion per quarter during the sample period. With a sixtyworkday quarter, daily production is $\$ 1.5$ billion. This calculation agrees with the 2.1 percent average absolute percentage error; 2.1 percent of sixty workdays is 1.3 days.

22. This conclusion is consistent with Lovell's judgment in 1967: "Firms now appear to be much more precise in predicting sales volume than is customarily assumed in theoretical models of the inventory cycle." Lovell based his conclusion on his finding in an analysis of the first five years of the current Commerce Department data that the average absolute percentage error was generally much smaller than that for the corresponding naive forecast. Lovell attributed this difference between his own finding and the finding of previous studies that "business firms are remarkably poor forecasters of future sales volume" to the fact that the Commerce data were better than those used in earlier research. (See "Sales Anticipations, Planned Inventory Investment, and Realizations," pp. 538, 542, respectively, for the quotations.) Our own analysis rejects Lovell's view that reported expectations are very much better than naive forecasts, perhaps because of our much larger sample and perhaps because of the seasonal-adjustment issue raised above. But we regard this difference in the assessment of forecast quality per se as much less important than our agreement that the errors are too small to be a source of substantial involuntary change in inventories. 
has the important implication that general adjustments to target levels of the stock of finished-goods inventories should occur at least as fast as changes to offset unanticipated sales changes.

\section{Inventories of Finished Goods}

As the introduction noted, the traditional parameter estimates of the equations for finished-goods inventories are inconsistent with the models on which those specifications are based. The nature of the conflict can now be summarized, with a more detailed analysis saved until some specific estimates have been presented. The basic problem lies in the estimated speed of adjustment of actual to desired inventory stocks. Previous investigators have interpreted their parameter estimates as implying that the gap between actual and desired inventories is reduced by only about 10 percent per quarter, or 35 percent per year. Such an extremely slow adjustment seems very unlikely, especially since a major inventory correction over an entire year is equivalent to, at most, a few days of production. ${ }^{23}$

The purportedly slow adjustment toward desired inventories also conflicts with the estimated effect of errors in sales forecasts. The typical error in forecasting quarterly sales is relatively large, as the discussion above demonstrated; the average forecast error was more than twice the size of the largest reduction in inventories of finished goods in the seventeen-year sample period. ${ }^{24}$ The very slow adjustment speed implies that almost all of the error in quarterly sales forecasts will show up as unwanted inventory accumulation or decumulation; for example, a $\$ 4$ billion underestimate of sales should reduce end-of-quarter finished-goods inventories by nearly $\$ 4$ billion. In fact, the estimated parameter values, from earlier estimates and from our own presented below, always imply a very small effect of the quarterly forecast error on the end-of-period inventory; the point estimates always indicate that 90 percent or more of the error is corrected within the quarter. The very slow estimated speed of inventory adjustment is thus in-

23. The 10 percent adjustment per quarter is an impressionistic average of published estimates that includes values between zero and 35 percent.

24. The average absolute error in forecasting quarterly sales was $\$ 2.0$ billion based on $S_{t, t}^{e}$ and $\$ 3.0$ billion based on $S_{t, t-1}^{e}$, while the largest reduction of finished-goods inventories was less than $\$ 1$ billion and occurred over one year and the largest one-year increase of finished-goods inventories was only $\$ 2$ billion. 
consistent with the rapid correction of forecast errors as well as with the basic data on the relative magnitude of inventory change and production.

We began our research with the belief that the basic adjustment-speed parameter had been grossly underestimated in previous studies. We anticipated that a more plausible value would emerge in the context of a more complex specification that was closer to the theoretical model of optimal inventory and production adjustment. For example, current inventory investment should reflect the lagged value of the past production level as well as such things as the level of capacity utilization and the number of laid-off employees receiving unemployment insurance. We also believed that the small value of the estimated stock-adjustment parameter reflected the inappropriate use of ordinary least squares in an equation in which the adjustment-speed parameter was derived from the coefficient of the lagged dependent variable.

Our empirical analyses led us to quite different conclusions. We now believe that the magnitudes of the previously reported coefficients of the lagged inventory and of the unanticipated sales change are basically correct. The conflict between the parameter estimates and the underlying theory is due not to incorrect coefficients but to the erroneous specification of the basic model in terms of which the coefficients have been interpreted.

We therefore propose replacing the traditional slow stock-adjustment model with an alternative, the "target-adjustment model." According to this model, inventories adjust completely within one quarter to the target level but this target level responds only slowly to changes in the fundamental determinants. This is just the opposite of the usual stock-adjustment model, in which the target adjusts completely within one quarter to changes in the fundamental determinants but the inventories themselves respond only slowly to changes in the target..$^{25}$ Before presenting this new model in more detail, we discuss estimates of the previous stock-adjustment model based on our new data. The results of our attempts to extend the model by adding the omitted features of the optimal inventory-production theory are presented in appendix A.

One cautionary note: Durable-goods manufacturing includes products that are produced to order as well as products that are produced to stock. Finished-goods inventories obviously relate almost exclusively to goods produced to stock. The data on sales, production, and orders deal with

25. Both models are special cases of a more general process that will be examined in M. Feldstein, "The Two-Speed Target-Stock Adjustment Model of Inventory Behavior." 
both types of goods. The changing ratio of the two introduces another source of variation and potential bias into our study. Analysis with more disaggregated data would eliminate or reduce this problem. We are therefore somewhat reassured that Belsley and Childs, who used two-digit data, encountered the same type of contradictory parameter values that we report here.

\section{THE BASIC STOCK-ADJUSTMENT MODEL FOR FINISHED GOODS}

The basic stock-adjustment model of inventory accumulation, as developed by Lovell and others, has two central ingredients: the stock of inventories changes (1) because firms partially close the gap between current desired inventories and the previous level of the stock, and (2) because of unanticipated changes in sales. More specifically,

$$
I_{t}-I_{t-1}=\lambda\left(I_{t}^{*}-I_{t-1}\right)+\delta\left(S_{t}^{e}-S_{t}\right),
$$

where $I_{t}$ and $I_{t}^{*}$ are actual and desired inventories of finished goods, respectively, at the end of quarter $t$, and $S_{t}$ and $S_{t}^{e}$ are actual and anticipated sales, respectively. ${ }^{26}$

If desired inventories depend linearly on current sales,

$$
I^{*}=\alpha_{0}+\alpha_{1} S_{t},
$$

and if sales expectations are based on the simplest "naive expectations" assumption that the current level of sales will continue into the next quarter $\left(S_{t}^{e}=S_{t-1}\right)$, then

$$
I_{t}-I_{t-1}=\lambda \alpha_{0}+\lambda \alpha_{1} S_{t}-\lambda I_{t-1}+\delta\left(S_{t-1}-S_{t}\right) .
$$

Estimating the parameters of equation 4 by ordinary least squares we obtain

$$
\begin{aligned}
& I_{t}-I_{t-1}=0.44+0.0073 S_{t}-0.057 I_{t-1}+0.044\left(S_{t-1}-S_{t}\right) . \\
& \begin{array}{lll}
(0.18) & (0.0036) \quad(0.017) & (0.010)
\end{array}
\end{aligned}
$$

$$
\begin{gathered}
\text { Sample period }=1961: 3-1976: 1 ;^{27} \bar{R}^{2}=0.29 ; \text { standard error }=0.20 ; \\
\text { Durbin-Watson }=1.22 .
\end{gathered}
$$

The coefficient of $I_{t-1}$ implies that less than 6 percent of the gap between

26. For simplicity's sake, in this section we use $I_{t}$ rather than $I F G_{t}$ to denote finishedgoods inventories since they are the only class of stocks discussed here.

27. We have dropped the first few quarters of our available data in order to use the same sample period that we are forced to use by the more limited availability of the survey data on sales expectations. 
desired inventories and last period's inventories is eliminated within one quarter, less than 25 percent within one year! In contrast, the estimate of $\delta$ implies that more than 95 percent of the effect of the "unanticipated" change in sales is corrected within the quarter. Since the average quarterly change in sales is much larger than the largest inventory decumulation, ${ }^{28}$ there is clearly something wrong with either these parameter estimates or their interpretation. ${ }^{29}$

If the disturbances are autocorrelated, ordinary least squares produces biased coefficients even in large samples when there is a lagged dependent variable among the explanatory variables..$^{30}$ As Liviatan first suggested, instrumental-variable estimation can yield consistent parameter estimates in this context. ${ }^{31}$ All subsequent regressions employ the instrumental-variable technique, except where noted. The instrumental-variable estimates presented in equation 6 show that the bias from this source is extremely small: $:^{32}$

$$
I_{t}-I_{t-1}=\underset{(0.18)}{0.44}+\underset{(0.0037)}{0.0070} S_{t}-0.056 I_{t-1}+\underset{(0.018)}{0.044}\left(S_{t-1}-S_{t}\right) .
$$

Sample period $=1961: 3-1976: 1 ;$ standard error $=0.20$; Durbin-Watson $=1.22$.

The very simple "naive expectations" sales forecast is clearly a misspecification and therefore a potential source of biased parameter estimates. In place of this assumption we therefore use the survey estimate $S_{t, t}^{e}$. Similarly, we shall assume that the desired end-of-period inventories $\left(I_{t}^{*}\right)$ toward which firms adjust is a function of these expected sales since actual

28. The average absolute value of $S_{t-1}-S_{t}$ was $\$ 2.25$ billion during the sample period, while the largest inventory decline was less than $\$ 1$ billion and took four quarters to occur.

29. The implied equilibrium relation of inventory to sales is plausible for the sample period: $I_{t}^{*}=\$ 7.72+0.13 S_{t}$, indicating some long-run economies of scale in inventory "requirements."

30. Note that rewriting equation 5 with $I_{t-1}$ on the left-hand side would do nothing but add 1 to the coefficient of $I_{t-1}$.

31. Nissan Liviatan, "Consistent Estimation of Distributed Lags," International Economic Review, vol. 4 (January 1963), pp. 44-52.

If the disturbances are known to follow a $k$ th-order autoregressive process, consistent and efficient estimates are obtained by a corresponding autoregressive transformation in which the autocorrelation coefficients are also estimated. We prefer the instrumentalvariable procedure because it is robust with respect to specification of the autoregressive process.

32. The instrumental variables are $S_{t}, S_{t-1}$, the money supply $\left(\mathrm{M}_{1}\right)$, the change in $\mathrm{M}_{1}$, exports, U.S. Department of Defense obligations, population, and a time trend. 
sales cannot be known until the end of the period. With these modifications, equation 6 becomes

$$
\begin{aligned}
I_{t}-I_{t-1}= & 0.22 \\
& (0.18)
\end{aligned}+\underset{(0.004)}{0.009} S_{t, t}^{e}-0.055 I_{t-1}+\underset{(0.018)}{0.037}\left(S_{t, t}^{e}-S_{t}\right) .
$$

Sample period $=1961: 3-1976: 1$; standard error $=0.20$;

Durbin-Watson $=1.24$.

The inventory-adjustment speed is essentially unchanged $(0.055)$ and still less than 10 percent per quarter, or 35 percent per year. The adjustment to the sales-forecast error is now even more nearly complete ( 96 percent per quarter) so that the conflict remains as large as ever.

We have experimented with several alternative specifications of desired inventory change and of unanticipated sales change. The fastest estimated inventory adjustment occurs when $I_{t}^{*}$ depends on expected sales in the next quarter $\left(S_{t+1, t}^{e}\right)$ :

$$
I_{t}-I_{t-1}=\underset{(0.19)}{0.016}+\underset{(0.004)}{0.011} S_{t+1, t}^{e}-0.065 I_{t-1}+\underset{(0.019)}{0.037}\left(S_{t, t}^{e}-S_{t}\right) .
$$

Sample period $=1961: 3-1976: 1$; standard error $=0.20$; Durbin-Watson $=1.24$.

But even here the speed of response (6.5 percent per quarter) is implausibly slow and in sharp contrast to the nearly complete elimination of the effect of unanticipated sales. Other small modifications of this specification do not alter the conclusion that the parameter estimates are not consistent with each other or with the basic characteristics of the data presented in the previous two sections.

In 1960, Holt, Modigliani, Muth, and Simon published their pioneering contribution to managerial economics, in which they showed firms how to lower total costs by applying mathematical procedures to production and inventory decisions. Although the book was intended as a prescriptive study, it is also valuable as a source of hypotheses about the actual behavior of firms. The linear-adjustment model implied by this theory has been estimated extensively, but the parameter estimates always indicate the same apparently slow adjustment of inventories and rapid correction of salesanticipation errors. Moreover, the specifications based on the model did not provide a superior statistical explanation of quarterly inventory changes. We nevertheless subjected that model to further analysis in the belief that our improved constant-dollar data and our new ideas about appropriate specification would yield fundamentally different parameter estimates. De- 
spite our best efforts, we found the same adjustment speeds in these more complex models and concluded that the extra complexity did not improve the statistical explanation of inventory investment. Appendix A summarizes the inventory equation implied by the model by Holt and his associates and presents some of our empirical estimates.

The repeated finding that the parameter estimates could not be reconciled with existing theory forced us to reexamine the basic theory itself. This led us to reject the traditional stock-adjustment model in favor of our alternative analytic framework.

\section{THE TARGET-ADJUSTMENT MODEL}

We turn at last to our own target-adjustment model of "immediate" inventory adjustment to a slowly changing inventory target. The new theory is consistent with the estimated parameter values and eliminates the apparent conflict between the "rapid response to unanticipated sales" and the "slow adjustment of stocks to the desired level." The current target-adjustment model is also compatible with the evidence on the relative magnitudes of production and inventory change. The new and specific restrictions implied by the model are supported by the data.

The first crucial feature of the new model is that the stock of inventories is now assumed to adjust within the quarter to the currently desired level except for a small effect of unanticipated sales:

$$
I_{t}=I_{t}^{*}+\gamma_{0}\left(S_{t, t}^{e}-S_{t}\right)+u_{t}
$$

where $u$ is the error term. Although such a specification stands in sharp contrast to the common lagged-adjustment model, it is a plausible ex ante specification on the basis of our analysis of the raw data on production levels and inventory changes. A change in inventory that is planned at the beginning of the quarter should be easy to achieve by the end of the quarter. In the same way, unanticipated changes in sales in the early part of the quarter should be easy to compensate for by the end of the quarter. Only the portion of unanticipated sales that occurs late in the quarter will go uncorrected to any significant degree. This implies that $\gamma_{0}$ should be positive but quite small.

The second important feature of the new model is the assumption that the firms' desired or target level of inventories adjusts slowly. Such slow adjustment can reflect a variety of quite different factors: basic inventory 
guidelines are often established in multiyear plans and revised only slowly; inventory targets depend on the company's warehousing facilities and personnel, which can adjust only slowly; learning may be slow because excess inventory costs little, and so on. The last point deserves further explanation. Consider a firm with relatively high finished-goods inventories equal to one month's sales. Assume that inventory carrying costs (interest, warehousing, "shrinkage") are a very high 25 percent per year. A 10 percent reduction in inventories saves only 10 percent of 25 percent of one-twelfth of annual sales-that is, 0.2 percent of sales. If before-tax profits are 7 percent of sales (the average in durables manufacturing for recent years), the reduced inventories can raise profits by no more than 3 percent $(0.002$ / 0.070 ). Against this small potential gain the firm must weigh the risk of running short and missing sales or of being forced to charge lower prices to keep customers who might otherwise be lost because of the more frequent stock-outs. It would not be surprising, therefore, if firms were very slow to change their target inventories as they learn from experience about the costs and benefits of different inventory policies in a changing economic environment. . $^{33}$

The simplest approximation of this slow revision of desired, or target, inventories is given by the adjustment equation:

$$
I_{t}^{*}-I_{t-1}^{*}=\mu\left(\gamma_{1}+\gamma_{2} S_{t, t}^{e}-I_{t-1}^{*}\right)+\epsilon_{t} .
$$

In this equation the target level of inventories adjusts to a linear function of expected sales. The speed of this target adjustment depends on the value of $\mu$. The random disturbances $\epsilon_{t}$ represent decision errors and other factors that change the target level of inventories. As Robert A. Gordon has pointed out, Keynes' theory of inventory cycles stressed that businessmen made such errors in setting their desired inventories, in contrast to Metzler's more mechanistic emphasis on the cycles generated in the absence of stochastic disturbances; the relative variance of $\epsilon_{t}$ can be taken as a measure of the importance of the Keynesian and Metzlerian influences. ${ }^{34}$

33. For a further discussion along these lines, see Ruth P. Mack, "Characteristics of Inventory Investment: The Aggregate and Its Parts," in National Bureau of Economic Research, Conference on Research in Income and Wealth, Problems of Capital Formation: Concepts, Measurement, and Controlling Factors (Princeton University Press for the National Bureau of Economic Research, 1957).

34. See the discussion in Robert A. Gordon, Business Fluctuations (2d ed., Harper and Row, 1961), pp. 348-52, and Keynes, General Theory, pp. 331-32. 
Substituting equation 10 into equation 9 yields

(11) $I_{t}=(1-\mu) I_{t-1}^{*}+\mu \gamma_{1}+\mu \gamma_{2} S_{t, t}^{e}+\gamma_{0}\left(S_{t, t}^{e}-S_{t}\right)+\left(u_{t}+\epsilon_{t}\right)$.

Such an equation cannot be estimated directly because $I_{t-1}^{*}$ is not observed. We can, however, obtain $I_{t-1}$ from a lagged version of equation 9 as

$$
I_{t-1}^{*}=I_{t-1}-\gamma_{0}\left(S_{t-1, t-1}^{e}-S_{t-1}\right)-u_{t-1} .
$$

Substituting into equation 10 yields the final equation of the target-adjustment model of inventory accumulation:

$$
\begin{aligned}
I_{t}= & (1-\mu) I_{t-1}-(1-\mu) \gamma_{0}\left(S_{t-1, t-1}^{e}-S_{t-1}\right) \\
& +\mu \gamma_{1}+\mu \gamma_{2} S_{t, t}^{e}+\gamma_{0}\left(S_{t, t}^{e}-S_{t}\right)+v_{t},
\end{aligned}
$$

where

$$
v_{t}=\epsilon_{t}+u_{t}-(1-\mu) u_{t-1} .
$$

Note that equation 13 contains an overidentifying restriction: the coefficient of the lagged unanticipated-sales term is $-(1-\mu) \gamma_{0}$, where $\gamma_{0}$ is the coefficient of the current unanticipated-sales term and $(1-\mu)$ is the coefficient of the lagged inventory term. In principle, we could test whether the parameter estimates are consistent with this formal restriction implied by the theory as well as with the general order-of-magnitude properties implied by the data.

The current target-adjustment model might be extended in a number of ways. Equation 9 could be extended to consider a more general model, in which the actual stock of inventories adjusts with a lag to the target whose evolution is governed by equation $10 .^{35} \mathrm{We}$ prefer, however, to focus on the current extreme target-adjustment form, both in order to emphasize the contrast with the traditional stock-adjustment form and because preliminary analysis of the data suggests that this extreme form is likely to be the appropriate specification. Equation 10 could also be generalized to examine

35. Readers should note that, except for the error-correction term $\left(S_{t, t}^{0}-S_{t}\right)$, the traditional stock-adjustment model of inventory accumulation is an example of a "partial adjustment" model of distributed-lag response while the target-adjustment model can be interpreted as an example of an "adaptive expectations" model; for a discussion of these two specifications and their statistical identification in general, see Zvi Griliches, "Distributed Lags: A Survey," Econometrica, vol. 35 (January 1967), pp. 16-49. In principle, the error-correction term permits a choice between the two specifications in the current context without assuming restrictions on the autoregressive structure of the residuals. The two-speed adjustment model (referred to in footnote 25) combines the partial-adjustment and adaptive-expectations approaches by keeping the specification of 10 but replacing 9 with an equation like 2 . 
whether the target rate is influenced by changes in the real interest rate, in liquidity, or in other factors. ${ }^{36}$ Again, we prefer to work with the simpler specification now and leave such possible generalizations for future research.

Our estimation of equation 13 supports the underlying target-adjustment model. The parameter values are of the expected magnitudes and the nonlinear parameter restriction is satisfied statistically. If the constraint implied by equation 13 is imposed and the unique value of $\gamma_{0}$ is obtained by searching over a grid of $\gamma_{0}$ values at intervals of 0.001 , the minimum residual sum of squares occurs at $\gamma_{0}=0.018$ (equation 14).

$$
\begin{aligned}
I_{t}= & 0.232+0.0077 S_{t, t}^{e}+0.018\left(S_{t, t}^{e}-S_{t}\right) \\
& (0.206)(0.0042) \\
& -0.017\left(S_{t-1, t-1}^{e}-S_{t-1}\right)+0.952 I_{t-1} .
\end{aligned}
$$

Sample period $=1961: 4-1976: 1 ;$ standard error $=0.20$;

Durbin-Watson $=0.77$.

The implied value of $\gamma_{2}=0.159$ is the marginal inventory-to-sales ratio.

Relaxing the constraint in equation 13 does not alter the relative magnitudes of any of the three coefficients but does cause the two point estimates of $\gamma_{0}$ to differ from the constrained value of 0.018 , as shown in equation 15. Although the constant might be rejected on formal statistical grounds, such a result should not be interpreted as a rejection of the entire targetadjustment model. ${ }^{37}$ The particular constraint in equation 13 reflects the

36. The results obtained with our experimentation induced us to try a specification in which the desired level of inventories adjusts to changes in production $\left(X_{t-1}\right)$ rather than expected sales. This alternative model had about equal explanatory power but appeared to involve misspecification of the adjustment to unanticipated sales.

37. We say "might" because formal inference is at best approximate in the current context: the coefficients have been estimated by instrumental variables, the sample contains only fifty-eight observations, the equation contains a lagged dependent variable, and the structure of the serial dependence of the disturbances is unknown. If we ignore these problems and use the likelihood-ratio test that would be appropriate for a "large sample" estimate based on ordinary least squares with no lagged dependent variable and serially unconnected residuals, the relevant asymptotic likelihood ratio test statistic for the constraint has a value of $-2 \ln (9.081 / 9.495)^{58 / 2}=2.59$, where 9.081 and 9.495 are the sums of squared residuals for the unconstrained and constrained specifications. With these assumptions, the test statistic is distributed as chi square with one degree of freedom. Since the critical chi-square value is 3.84 for a 0.05 level of significance and 2.71 for a 0.10 level of significance, the constraint would not be rejected. Jerry Hausman has pointed out to us that if the serial correlation were a simple first-order process, correcting (while maintaining the other assumptions) would almost certainly lead to rejection of the constraint. The correct conclusion for the relevant, more general, problem is an open question. 
very simple specification of target determination in equation 10. A more general model of target determination would imply a different constraint. ${ }^{38}$

$$
\begin{aligned}
I_{t}= & 0.209+0.011 S_{t, t}^{e}+0.037\left(S_{t, t}^{e}-S_{t}\right) \\
& (0.194)(0.004) \quad(0.010) \\
& +0.008\left(S_{t-1, t-1}^{e}-S_{t-1}\right)+0.940 I_{t-1} . \\
& (0.012)
\end{aligned}
$$

Sample period $=1961: 4-1976: 1 ;$ standard error $=0.20$;

Durbin-Watson $=0.61$.

The value of $\gamma_{2}=0.168$ implied by equation 15 is quite similar to the corresponding estimate of $\gamma_{2}=0.159$ in equation 14 .

The parameter estimates imply that the target adjusts very slowly to the changing level of sales and that firms are able to correct more than 95 percent of the impact of the unanticipated sales within the quarter. This essentially complete correction supports our assumption that the stock adjusts completely to its current target within one quarter.

Note that the standard error of the regression corresponds to a relatively large unexplained variance of quarterly rates of accumulation of finishedgoods inventories. Only about one-third of the variance of DIFG is explained by the model. To some extent this probably reflects the problem of relating inventories of goods produced to stock to the sales and sales expectations of all types of goods. But the large unexplained variance also supports Keynes' view that much of the cyclical variation in inventories of finished goods arises from businessmen's errors, changing business confidence, and other psychological aspects of investment behavior. We believe that the assumption of complete stock adjustment to a slowly changing target is both reasonable a priori and supported by the regression equations. It would be desirable to test it, by regarding the target-adjustment model as a possible special case of the two-speed adjustment model. Although such an analysis seems most promising with monthly data, unfortunately sales expectations are surveyed only on a quarterly basis. ${ }^{39}$

38. The test implied by the constraint in equation 13 depends crucially on the salesexpectations data. It would clearly be inappropriate to base a test of the target-adjustment model on data with such obvious weaknesses.

39. Although the Bureau of Economic Analysis collects data on anticipated inventories, they cannot be used for a direct test of the assumption of complete stock adjustment because the relevant $I_{t}^{*}$ variable of equation 10 is not the value as planned at the beginning of the quarter but as revised during most of the quarter. Moreover, the reported "anticipated" inventory need not correspond to "desired" inventory so no direct test is provided. Nevertheless, some insight is likely to be gained by analyzing these data 
To conclude: while other specifications of the adjustment of target inventories to sales and other variables deserve examination, we believe that the basic idea of rapid adjustment of finished-goods inventories to slowly changing inventory targets will be borne out by future research.

\section{Inventories of Materials and Goods in Process}

Although inventories of materials and goods in process are more than three times as large and as volatile as inventories of finished goods, they have received less attention in econometric research. The theory of these inventories is less well developed, particularly with respect to their link with production and completions. The subject has benefited, however, from the insights and analysis of Stanback, Abramovitz, Holt and Modigliani, Lovell, and Trivedi. ${ }^{40}$

Our research here begins by developing an explicit stock-adjustment model of the behavior of inventories of materials and goods in process $(I M G)$, with specific attention to the ideas that current deliveries of materials reflect previous (unobservable) orders for materials and that the current change in materials inventories is equal to these deliveries minus the materials used up in current production. Similarly, our analysis of inventories of goods in process emphasizes the links among production, completions, and the stock of such inventories. Although the available data do not permit separate analysis of the two components of $I M G$, a model for the total can be developed. Indeed, as Abramovitz and others have noted, strong analytic reasons argue for considering the two together because goods in process held as inventories between stages of production will often be a good substitute for larger materials inventories.

The resulting model of inventory investment governed by delivery lags and production links involves many long distributed lags. Once again, our econometric analysis leads us to reject such a model in favor of a targetadjustment model in which firms are able to adjust $I M G$ to their desired level within a single quarter.

in the framework of the target-adjustment model. Unfortunately, the BEA does not collect these data by stage of fabrication.

40. Thomas M. Stanback, Jr., Postwar Cycles in Manufacturers' Inventories (National Bureau of Economic Research, 1962); Abramovitz, Inventories and Business Cycles; Holt and Modigliani, "Firm Cost Structures"; Lovell, "Factors Determining Manufacturing Inventory Investment"; Trivedi, "Time Series Versus Structural Models." 
A few words about the data are in order. The data on inventories of materials and goods in process cover firms that produce to order as well as those that produce to stock. Therefore, no problem arises in comparing sales and orders with inventories as it might for finished-goods inventories. This coverage also permits the analysis of lagged unfilled orders as a determinant of inventory accumulation. ${ }^{41}$ Two potential problems should be borne in mind. Measures of the actual stock of inventories exclude both contracts that firms have with suppliers for future deliveries and futures contracts that the firms have taken in organized commodity exchanges. The model incorporates the unobservable supplier contracts for future delivery, which are solved out to obtain a model that can be estimated. Insofar as dealings in commodity futures are a substitute for contracts with suppliers, they raise no new problem. They do differ, however, in that they allow firms to speculate or hedge against price movements without taking or planning to take actual possession of physical inventories. Although this possibility must qualify our conclusions, organized markets in futures exist for relatively few commodities purchased by durables manufacturers. The second problem is that the stock-adjustment theory of $I M G$ investment that we shall develop is really a theory of $I M G$ demand combined with fixed delivery lags. Actual delivery lags might vary with demand conditions and confound the interpretation of demand variables, a point noted by Lovell. Here the potential problem could be solved only with disaggregated data that permit judging changes in supply conditions by measuring the stock of unfilled orders of supplier industries.

\section{THE DELAYED-STOCK-ADJUSTMENT MODEL OF IMG INVESTMENT}

The model rests on a behavioral equation for investment in materials inventories $\left(D I M_{t}\right)$. This is combined with a production identity for investment in goods in process $\left(D I G_{t}\right)$ to yield an estimable equation for the combined investment in materials and goods in process $\left(D I M G_{t}\right)$.

The accumulation of materials inventories represents the difference between deliveries received $\left(D_{t}\right)$ and materials withdrawn from inventory for use in production $\left(W_{t}\right)$. Deliveries represent orders placed during the cur-

41. Note that, as Childs, Unfilled Orders and Inventories, emphasized, unfilled orders are a decision variable of the firm so that a firm's current unfilled orders cannot be included as a determinant of its current inventory behavior. Unfilled orders should obviously not be included in the study of finished goods produced to stock. 
rent and past quarters $\left(O_{t}, O_{t-1}, \ldots\right)$. The model of materials accumulation must therefore begin with the determinants of the orders that firms place with their suppliers and then derive the determinants of current deliveries.

Firms place orders for materials on the basis of anticipated production, the time required to obtain delivery, the existing stocks of materials and goods in process, and the backlog of unfilled orders for such materials. For firms producing to stock, anticipated production will depend on expected sales, past new orders, and the lagged values of completions and finishedgoods inventories, as explained in connection with appendix equation A-1. For firms producing to order, there is no inventory of finished goods but there is a backlog of unfilled orders $\left(U O_{t-1}\right)$. The flow of materials orders at time $t$ can be written in terms of these predetermined variables as ${ }^{42}$

$$
\begin{aligned}
O_{t}=a_{0}+a_{1} X_{t-1}+a_{2} I F G_{t-1} & +a_{3} N O_{t-1}+a_{4} N O_{t-2} \\
+a_{5} N O_{t-3}+a_{6} U O_{t-1} & +a_{7} I M G_{t-1} \\
& +a_{8}\left(\sum_{j=1}^{\infty} O_{t-j}-\sum_{j=1}^{\infty} D_{t-j}\right),
\end{aligned}
$$

where $N O$ is new orders and $X_{t}$ is the value of goods whose production is completed in period $t$. Note that the final term represents the backlog of orders for materials that have been placed but not yet filled. Note also the simplifying assumption that orders are affected in the same way by existing stocks of materials and of goods in process.

Deliveries are in general a weighted sum of current and past orders: ${ }^{43}$

$$
D_{t}=\sum_{k=0}^{k} l_{k} O_{t-k}
$$

Equations 16 and 17 can in principle be solved jointly to eliminate the materials-orders variables $\left(O_{t}\right.$ and $\left.O_{t-j}\right)$ and to express current deliveries as a distributed-lag function of new orders and unfilled orders to the firm $\left(N O_{t-1}\right.$ and $\left.U O_{t-1}\right)$, completions, and inventory variables that appear in equation 16 . These distributed lags would be infinitely long because

42. We exclude $S_{t, t}^{e}$ and $S_{t+1, t}^{e}$ because these are endogenous for firms that produce to order and that can vary their backlog of unfilled orders. New orders are assumed here to be exogenous although in fact firms can influence future new orders by their price and other selling policies.

43. Cancellations of existing orders pose a problem for this specification. If $O_{t}$ refers to new orders minus cancellations, the lag structure cannot be assumed to remain fixed. We assume here that cancellations are small enough not to change the lag structure. We will return to this problem below in presenting our own current-adjustment model. 
of the last term of equation $16 .{ }^{44}$ Note that such long distributed lags would apply to all of the product-order, completions, and inventory variables of that equation:

$$
D_{t}=a_{0}^{\prime}+\sum_{k=1}^{\infty} a_{1 k}^{\prime} X_{t-k}+\sum_{k=1}^{\infty} a_{2 k}^{\prime} I F G_{t-k}+\ldots
$$

This distributed-lag, stock-adjustment specification can be contrasted with the much simpler equation that results if the deliveries depend only on current orders - that is, if the delivery lag is less than the length of the sampling period $\left(l_{k}=0\right.$ for $k>0$ and $l_{0}=1$ ). The last term of equation 16 is then identically zero and $D_{t}=O_{t}$, so that

$$
\begin{aligned}
D_{t}= & a_{0}+a_{1} X_{t-1}+a_{2} I F G_{t-1}+a_{3} N O_{t-1}+a_{4} N O_{t-2} \\
& +a_{5} N O_{t-3}+a_{6} U O_{t-1}+a_{7} I M G_{t-1} .
\end{aligned}
$$

Estimating a finite lag approximation to equation 18, and comparing it to the estimate of equation 19, yields valuable information about the nature of the delivery lags and therefore about the extent to which firms must look to future production in placing materials orders. Although such deliveries are not actually observable, the relevant estimation can be carried out after the remainder of the model is specified.

Net investment in materials is the difference between deliveries and withdrawals for current production:

$$
I M_{t}=I M_{t-1}+D_{t}-W_{t} .
$$

Production $\left(Q_{t}\right)$ should, of course, be distinguished from completions $\left(X_{t}\right)$; production involves additions to inventories of goods in process while completions involve withdrawals. The ratio of materials used to the value of current production varies over time with changes in technology and in relative prices. The subsequent exposition will be aided by expressing the withdrawals of materials for use in production as a function of the rate of production:

$$
W_{t}=\phi_{t} Q_{t} .
$$

Since $\phi_{t}$ is allowed to vary with $t$, equation 21 involves no restriction. With this notation, investment in materials can be written

$$
D I M_{t}=D_{t}-\phi_{t} Q_{t}
$$

where $D_{t}$ is given by equation 18 .

44. "Infinitely long" lags are clearly a shorthand in this context for "as long as firms have been placing orders for materials." 
The inventory of goods in process rises whenever production occurs until the work in process becomes a finished good and is sold or moved into the inventory of finished goods:

$$
I G_{t}=I G_{t-1}+Q_{t}-X_{t} .
$$

Investment in these inventories can therefore by expressed as

$$
D I G_{t}=Q_{t}-X_{t} .
$$

Combining equations 22 and 24 yields the stock-adjustment equation for investment in materials and goods in process:

$$
D I M G_{t}=D_{t}-\phi_{t} Q_{t}+Q_{t}-X_{t},
$$

where $D_{t}$ is given by equation 18 . The term $Q_{t}-\phi_{t} Q_{t}$ is the difference between the total value of production and the value of the materials used up in production; that is, $Q_{t}-\phi_{t} Q_{t}$ is equal to value added. Denoting this expression as $V_{t}$, and rewriting equation 25 , yields

$$
D I M G_{t}=D_{t}+V_{t}-X_{t} ;
$$

investment in materials and goods in process is equal to the value of materials delivered plus the value added by production during the period minus the value of the completed goods withdrawn from goods in process.

Because previous studies of investment in materials and goods in process have ignored $V_{t}$ and $X_{t}$, we have gone through this laborious derivation precisely to emphasize the role of these variables. The implication that $V_{t}$ enters the equation for DIMG with a coefficient of 1 while $X_{t}$ enters with a coefficient of -1 provides a further way of testing the consistency of the parameter estimates with the lagged stock-adjustment theory. ${ }^{45}$

We have estimated equation 26 with a wide variety of alternative approximations to the delivery specification of equation 18 . The parameter estimates were always in conflict with the theoretical implications of the stock-adjustment model. First, there was no evidence of the longer lags characteristic of equation 18 . The pattern of lags was consistent with the current-period delivery specification of 19 . Second, the coefficients of the

45. For durable-goods manufacturing, the value of completions averages about three times the concurrent value added. The difference in any quarter represents both the value of materials and the variation in the timing of production and completions. Data on value added in durables manufacturing is prepared by the Department of Commerce only on an annual basis; we derived quarterly values consistent with these annual totals by interpolating with the Federal Reserve Board index of industrial production for durables manufacturing. 
value-added and completions variables were very different from the theoretical predictions.

For example, equation 27 (estimated by ordinary least squares) is typical of the results obtained when even a two-quarter distributed lag is specified. The longer lags are either insignificant or, more important, have the wrong sign.

$$
\begin{aligned}
& I M G_{t}-I M G_{t-1}=-1.692+0.12 X_{t-1}-0.10 X_{t-2} \\
& \quad(0.548)(0.08) \quad(0.04) \\
& +0.085 I F G_{t-1}+0.034 I F G_{t-2}-0.084 N O_{t-1} \\
& \quad(0.266) \quad(0.262) \quad(0.077) \\
& +0.067 N O_{t-2}+0.025 N O_{t-3}-0.004 N O_{t-4} \\
& \quad(0.033) \quad(0.021) \quad(0.017) \\
& +0.141 U O_{t-1}-0.115 U O_{t-2} \\
& \quad(0.083) \quad(0.083) \\
& -0.147 I M G_{t-1}+0.027 I M G_{t-2}+0.063 V_{t}+0.001 X_{t .} . \\
& (0.130) \quad(0.121) \quad(0.079) \quad(0.039)
\end{aligned}
$$

Sample period $=1959: 3-1975: 4$; standard error $=0.38$;

Durbin-Watson $=1.82$.

The coefficients of current value added and completions are far from the theoretical predictions of +1 and -1 , but not significantly different from zero.

In the simpler specification based on current-period deliveries (that is, with $D_{t}$ given by equation 19), the coefficients become more plausible and the explanatory power of the equation is not reduced (again, ordinary least squares).

$$
\begin{gathered}
I M G_{t}-I M G_{t-1}=-1.881-0.015 X_{t-1}+0.137 I F G_{t-1} \\
\quad(0.531)(0.035) \quad(0.111) \\
+0.038 N O_{t-1}+0.009 N O_{t-2}+0.011 \mathrm{NO}_{t-3} \\
\quad(0.022) \quad(0.002) \quad(0.016) \\
+0.026 U O_{t-1}-0.160 I M G_{t-1}+0.115 V_{t}-0.020 X_{t .} . \\
(0.012) \quad(0.036) \quad(0.076)
\end{gathered}
$$

Sample period $=1959: 3-1975: 4 ;$ standard error $=0.39$;

Durbin-Watson $=1.71$.

The omission of five variables in going from equation 27 to equation 28 increases the sum of squared residuals only from 7.269 to 8.471 ; the corresponding $F$ statistic is only 1.65 while the critical value for a 0.05 level of significance is 2.40 . The simpler current-delivery model cannot be re- 
jected in favor of a longer-lagged adjustment process. Further experiments confirm that the coefficient of $I M G_{t-2}$ is never significant in the way that it should be if current deliveries were reflecting orders placed in period $t-1$ in response to $I M G_{t-2}$.

But even the current-adjustment specification of equation 28 is clearly not satisfactory. The coefficients of $V_{t}$ and $X_{t}$ do not conform to the theoretical prediction. The lagged stock of finished goods and the lagged completion rate are both statistically insignificant, casting doubt on the relevance of the full optimal-production model as a basis for quarterly adjustments of $I M G$. Moreover, the small coefficient of $I M G_{t-1}$ implies an extremely slow rate of stock adjustment that is inconsistent with the relative magnitudes of changes in $I M G$ and rates of materials acquisition and production.

\section{THE TARGET-ADJUSTMENT MODEL OF IMG INVESTMENT}

We turn again to a model of inventory accumulation in which firms adjust inventories to their desired target within a single quarter while the target itself adjusts more slowly to changes in its fundamental determinants. There is evidence to support the choice of such a current-quarter adjustment of actual inventories. In discussing the basic characteristics of the data, we noted that even the largest decumulation of $I M G$ required the elimination of at most five days of materials deliveries or three days of production during a span of five quarters. The accumulation of materials can be reduced even more easily and with even less cost than the accumulation of finished goods, simply by canceling outstanding orders (and without penalty from suppliers, as Stanback has emphasized). On the other hand, the possibility of increasing inventories of materials to a desired level within the quarter is supported by survey evidence collected by the National Association of Purchasing Agents: 91 percent of purchasing agents reported delivery times of sixty days or less in the cyclical trough of 1958 while 77 percent reported such delivery times even in the cyclical-peak months of 1957 and $1960 .{ }^{46}$

In keeping with the assumption that firms can get the orders delivered within the same quarter $\left(D_{t}=O_{t}\right)$, we posit that firms place orders to close the gap between past and target inventories $\left(I M G_{t}^{*}-I M G_{t-1}\right)$ as well as to replace the materials that they expect to use up $\left(\phi_{t} Q_{t}\right)$ and the

46. Stanback, Postwar Cycles. 
finished goods they expect to withdraw net of the new production that adds to goods in process $\left(X_{t}-Q_{t}\right)$. Thus,

$$
O_{t}=I M G_{t}^{*}-I M G_{t-1}+\phi_{t} Q_{t}+X_{t}-Q_{t}+\nu_{t},
$$

where $\nu_{t}$ is a random disturbance that reflects firms' errors. Since $\left(1-\phi_{t}\right) Q_{t}$ is value added, equation 29 can be written alternatively as

$$
O_{t}=I M G_{t}^{*}-I M G_{t-1}+X_{t}-V_{t}+\nu_{t} .
$$

Equation 27 shows that actual inventories change according to

$$
I M G_{t}-I M G_{t-1}=D_{t}+V_{t}-X_{t} .
$$

Combining equations 30 and 31 with the assumption of concurrent delivery $\left(D_{t}=O_{t}\right)$ yields

$$
I M G_{t}=I M G_{t}^{*}+\nu_{t} .
$$

It is not necessary to repeat here all the reasons why firms adjust their targets only slowly to changes in the fundamental determinants: the nature of the institutional planning process by which inventory policy is determined, the physical constraints of warehousing and personnel, the cautious revision of targets under uncertainty, and so on. Firms adjust their target level of inventories in response to changes in their backlog of unfilled orders and their flow of new orders; since we are concerned with the target for inventory accumulation during period $t$, the variables are unfilled orders at the end of $t-1$ and new orders received in $t-1$. Both indicate the likely strength of future demand that makes it advisable to shift the target level of $I M G$. Although an increased backlog of unfilled orders may induce firms to increase deliveries of materials for production at once, there is no such necessary connection between unfilled orders and the actual level of inventories at the end of the next quarter; rather, more unfilled orders affect the target level of inventories by indicating a general strength of demand. Similarly, an increased flow of new orders may be regarded as affecting the firm's longer-term outlook and causing a gradual target adjustment. Thus, ${ }^{47}$

$$
I M G_{t}^{*}-I M G_{t-1}^{*}=\eta\left(b_{0}+b_{1} N O_{t-1}+b_{2} U O_{t-1}-I M G_{t-1}^{*}\right)+\xi_{t} .
$$

Substituting equation 33 into equation 32 and using the fact that

$$
I M G_{t-1}=I M G_{t-1}-\nu_{t-1}
$$

47. The empirical importance of both new orders and unfilled orders as determinants of $I M G$ has been discussed by Abramovitz, Stanback, Lovell, and others in papers previously cited. 
implies

$$
I M G_{t}=\eta b_{0}+\eta b_{1} N O_{t-1}+\eta b_{2} U O_{t-1}+(1-\eta) I M G_{t-1}+\nu_{t},
$$

where $\nu_{t}$ is a composite disturbance term. There is no overidentifying restriction in equation 34 because nothing in the current process is analogous to the role of unanticipated sales in finished-goods inventories.

Equation 35 presents the parameters of equation 34 :

$$
\begin{aligned}
& \text { (35) } I M G_{t}=-1.266+0.060 N O_{t-1}+0.020 U O_{t-1}+0.896 I M G_{t-1} \text {. } \\
& \begin{array}{lll}
(0.260)(0.007) \quad(0.007) \quad(0.009)
\end{array} \\
& \text { Sample period }=1959: 2-1976: 1 ; \text { standard error }=0.40 \text {; } \\
& \text { Durbin-Watson }=1.82 \text {. }
\end{aligned}
$$

The coefficients are estimated quite precisely and, as seen in the framework of the target-adjustment model, are of plausible sizes. Adding the current quarter's flow of new orders has little effect on the change in target inventories. An alternative modification, replacing $N O_{t-1}$ by lagged completions $\left(X_{t-1}\right)$, produces similar results. It is clear that richer data are needed to distinguish among alternative target-adjustment models.

\section{Explaining Inventory Behavior in 1974 and 1975}

Inventories of durable-goods manufacturing establishments rose throughout 1974 as the economic storm gathered, and then fell sharply in 1975 as the recession deepened. Some observers have expressed surprise at this behavior. Why did inventories continue to increase in 1974 with a recession already under way? And why didn't the involuntary accumulation of inventories prevent a drop in inventory levels in 1975 when the recession worsened?

The predictions generated by the target-adjustment equations for 1974 and 1975 indicated that there was actually nothing surprising about the general behavior of durables-manufacturing inventories in those years, given the behavior of orders and other determinants of inventory holdings. More specifically, we have reestimated equations 14 and 35 for the period ending in 1973:4 and then calculated predicted inventories for the next nine quarters, using the actual values of sales, orders, and so forth, but the endogenously generated values of lagged inventories. The separate predictions for finished goods and for materials and goods in process were combined to obtain a total predicted inventory for each quarter. Table 3 compares 
Table 3. Actual and Predicted Inventories in Durables-Manufacturing Industries, 1974:1-1976:1

Billions of 1972 dollars, seasonally adjusted

\begin{tabular}{rrrrrr}
\hline \multirow{2}{*}{$\begin{array}{c}\text { Year and } \\
\text { quarter }\end{array}$} & Level & Change & & \multicolumn{2}{c}{ Aredicted } \\
\cline { 2 - 3 } \cline { 5 - 6 } \cline { 5 - 6 } $1974: 1$ & 84.3 & 1.5 & & 84.18 & Level \\
2 & 84.5 & 0.2 & & 85.27 & Change \\
3 & 85.2 & 0.7 & & 86.52 & 1.38 \\
4 & 86.3 & 1.1 & & 87.21 & 1.25 \\
$1975: 1$ & 86.4 & 0.1 & & 86.49 & 0.69 \\
2 & 85.2 & -1.2 & & 84.77 & -0.72 \\
3 & 83.6 & -1.6 & & 83.52 & -1.72 \\
4 & 82.5 & -1.1 & & 82.62 & -0.90 \\
$1976: 1$ & 81.7 & -0.8 & & 81.68 & -0.94 \\
\hline
\end{tabular}

Sources: Actual inventories are from Survey of Current Business, vol. 56 (January 1976), pt. 2, and vol. 56 (June 1976). For predictions, equations 14 and 35 in the text were reestimated through 1973:4. Predicted inventories, based on separate equations for finished goods and for materials and goods in process, were calculated for the next nine quarters, using actual values of sales, orders, and so forth, but endogenously generated values of lagged inventories.

the actual and predicted values of inventories and of the quarterly changes in inventories.

Inventories rose in each quarter of 1974 , behavior that is correctly predicted by the inventory equations. Inventory change became negative in 1975:1 and stayed negative for the remaining four quarters of the sample, developments that are correctly predicted by the equations. The relative magnitudes of the actual and predicted changes are also generally in accord although the magnitude of actual decumulation lagged slightly behind the predictions. The levels are predicted quite accurately at both the beginning and the end of the prediction interval.

The performance of our simple equations may seem surprising in light of the omission of some of the economic events of 1974 and 1975 that might be thought to have had a major impact on inventory accumulation. Wholesale prices rose dramatically in 1974: the price index of materials used for durables manufacturing rose 29 percent from January 1974 to January 1975 and the price index for durable finished goods rose 21 percent, while these prices remained relatively constant in 1975 . Interest rates reached peak levels in 1974, with the commercial paper rate hitting nearly 12 percent in July 1974 before falling to below 6 percent less than a year later. Firms were still reacting to the oil embargo and to the scarcities caused by price con- 
Table 4. Fundamental Determinants of Durables-Manufacturing Inventories, 1973:4-1976:1

Billions of 1972 dollars, seasonally adjusted

\begin{tabular}{|c|c|c|c|c|c|c|c|}
\hline \multirow[b]{2}{*}{$\begin{array}{l}\text { Year } \\
\text { and } \\
\text { quarter }\end{array}$} & \multirow[b]{2}{*}{$\begin{array}{c}\text { New } \\
\text { orders } \\
\left(N O_{t}\right) \\
(l)\end{array}$} & \multirow[b]{2}{*}{$\begin{array}{c}\text { Unfilled } \\
\text { orders } \\
\left(U O_{t}\right) \\
(2)\end{array}$} & \multirow[b]{2}{*}{$\begin{array}{c}\text { Expected } \\
\text { sales } \\
\left(S_{t}^{e}, t\right) \\
(3)\end{array}$} & \multirow[b]{2}{*}{$\begin{array}{l}\text { Unantici- } \\
\text { pated } \\
\text { sales } \\
\left(S_{t}-S_{t, t}^{e}\right) \\
\quad(4)\end{array}$} & \multirow[b]{2}{*}{$\begin{array}{c}\text { Actual } \\
\text { sales } \\
\left(S_{t}\right) \\
(5)\end{array}$} & \multicolumn{2}{|c|}{$\begin{array}{l}\text { Ratio of expected sales } \\
\text { to lagged inventories }\end{array}$} \\
\hline & & & & & & $\begin{array}{c}\text { Total } \\
\left(S_{t, t}^{e} /\right. \\
\left.I M G_{t-1}\right) \\
(6)\end{array}$ & $\begin{array}{c}\text { Finished } \\
\text { goods } \\
\left(S_{t, t}^{e},\right. \\
\left.I F G_{t-1}\right) \\
(7)\end{array}$ \\
\hline $1973: 4$ & 118.3 & 104.0 & 108.8 & 2.8 & 111.5 & 1.76 & 5.63 \\
\hline 1974:1 & 114.5 & 105.8 & 102.5 & 6.2 & 108.6 & 1.61 & 5.36 \\
\hline 2 & 116.3 & 108.2 & 103.6 & 4.0 & 107.6 & 1.59 & 5.43 \\
\hline 3 & 112.2 & 108.9 & 108.7 & -3.7 & 104.9 & 1.65 & 5.76 \\
\hline 4 & 95.0 & 101.0 & 100.4 & -1.7 & 98.7 & 1.51 & 5.21 \\
\hline $1975: 1$ & 82.0 & 92.2 & 92.8 & -4.0 & 88.8 & 1.39 & 4.70 \\
\hline 2 & 86.5 & 87.9 & 94.4 & -4.0 & 90.4 & 1.43 & 4.69 \\
\hline 3 & 92.3 & 86.6 & 99.2 & -6.1 & 93.2 & 1.52 & 4.94 \\
\hline 4 & 90.9 & 82.6 & 91.4 & 1.3 & 92.7 & 1.44 & 4.58 \\
\hline 1976:1 & 95.9 & 80.2 & 92.2 & 4.9 & 97.1 & 1.44 & 4.71 \\
\hline
\end{tabular}

Source: See appendix B. Figures are rounded.

trols in earlier years. And yet, while we do not dismiss these factors out of hand, the data on orders, sales expectations, and so on, reveal why our simple target-adjustment equations were able to predict inventory behavior quite well.

Table 4 presents the values of these fundamental variables for the period 1973:4 to 1976:1. Recall first that target inventories of materials and goods in process are influenced strongly by the lagged values of new orders $\left(N O_{t-1}\right)$ and unfilled orders $\left(U O_{t-1}\right)$. Despite the recession, neither new nor unfilled orders showed any significant decrease until the fourth quarter of 1974. Their holding up that long helped to support inventories during 1974. If there is a surprise in inventory behavior, it can be traced to the sustained level of new orders during the early stage of the recession. Their sharp drop in 1974:4 contributed to the fall in inventories of materials and goods in process in 1975:1. The ratios of expected sales to the lagged values of all durable-goods inventories (column 6) and of durable finished-goods inventories (column 7) also declined sharply in 1974:4 and 1975:1. Although examining table 4 in this way is simply a crude approximation to estimating 
Table 5. Inventory Behavior, 1974:1-1976:1

Billions of 1972 dollars, seasonally adjusted

\begin{tabular}{|c|c|c|c|c|c|c|c|c|}
\hline \multirow{2}{*}{$\begin{array}{l}\text { Year } \\
\text { and } \\
\text { quarter }\end{array}$} & \multicolumn{2}{|c|}{ All business } & \multicolumn{2}{|c|}{ All manufacturing } & \multicolumn{2}{|c|}{$\begin{array}{c}\text { Durables } \\
\text { manufacturing }\end{array}$} & \multicolumn{2}{|c|}{$\begin{array}{l}\text { Nondurables } \\
\text { manufacturing }\end{array}$} \\
\hline & Level & Change & Level & Change & Level & Change & Level & Change \\
\hline 1974:1 & 296.7 & 2.8 & 125.7 & 2.1 & 84.3 & 1.5 & 41.4 & 0.7 \\
\hline 2 & 299.1 & 2.4 & 127.4 & 1.7 & 84.9 & 0.6 & 42.5 & 1.1 \\
\hline 3 & 300.3 & 1.2 & 128.6 & 1.2 & 85.7 & 0.8 & 42.9 & 0.4 \\
\hline 4 & 302.3 & 2.0 & 129.7 & 1.1 & 86.4 & 0.7 & 43.3 & 0.4 \\
\hline 1975:1 & 297.2 & -5.1 & 128.7 & -1.0 & 86.3 & -0.1 & 42.5 & -0.8 \\
\hline 2 & 291.9 & -5.3 & 126.6 & -2.1 & 85.2 & -1.1 & 41.4 & -1.1 \\
\hline 3 & 291.7 & -0.2 & 125.0 & -1.6 & 83.6 & -1.6 & 41.5 & 0.1 \\
\hline 4 & 290.3 & -1.4 & 124.1 & -0.9 & 82.1 & -1.5 & 41.9 & 0.4 \\
\hline 1976:1 & 292.9 & 2.6 & 124.1 & 0.0 & 81.4 & -0.7 & 42.7 & 0.8 \\
\hline
\end{tabular}

Source: See appendix B.

the inventory equations themselves, it does help to explain why our equations worked quite well for 1974-75. This kind of analysis of the raw data also provides further support for the target-adjustment model by showing that the inventories adjusted quite rapidly in this period to new orders, anticipated sales, and the like.

Table 5 shows that other business inventories also continued to rise in 1974 and turned down in the first quarter of 1975 at the same time as those in durables manufacturing. The very sharp fall in nonmanufacturing inventories is unusually large and indicates a quantitatively atypical response that deserves further analysis.

\section{Concluding Comments}

The thrust of this paper is easily summarized. We have examined a wide variety of specifications of inventory-investment equations for finished goods and for materials and goods in process. In each case, we reject the common stock-adjustment model as incompatible with the estimated parameter values. We have proposed an alternative "target-adjustment model" of inventory behavior, which is consistent with the estimated parameter values and with the basic characteristics of inventories and sales expectations. 
The key idea of the target-adjustment model in the current context is that inventories adjust completely within one quarter to the target level while the target level itself responds only slowly to changes in the fundamental determinants. These speeds of response are just the opposite of those in the usual stock-adjustment model: there, the target adjusts completely within one quarter to changes in its fundamental determinants while the inventories themselves respond only slowly to changes in the target.

The target-adjustment model offers a framework for more elaborate analyses than those presented here. For example, because of the structure of the model (in particular, the overidentifying restriction that arises when a variable enters the inventory-adjustment equation directly rather than through the target-adjustment process), it would be possible to estimate whether monetary policy, if effective at all, influences the inventory target or the achievement of that target.

Furthermore, a new set of data that we are developing but that was not available in time for this paper will make it possible to study real inventory investment for two-digit industries with a division for each industry into three stages of fabrication. Such disaggregated data will permit an analysis of the effects of changing availability as measured by suppliers' backlogs as well as a better distinction between goods produced to order and goods produced to stock.

Finally, we are aware that we have not analyzed the implications for macroeconomic stability of our empirical conclusions. We have established a theoretical foundation within which quarterly inventory accumulation is effectively independent of unanticipated sales, but we have not examined the significance of this departure from previous models of the inventory cycle. We have also provided a theoretical justification for the long lags between changes in new orders and the resulting changes in inventory investment without analyzing their macroeconomic implications. We hope that establishing the basic behavioral parameters on a firmer theoretical foundation will lend impetus to such analysis. 


\section{APPENDIX A}

\section{The Optimal-Production \\ and Stock-Adjustment Model}

IN THEIR fundamental contribution to managerial economics, Holt, Modigliani, Muth, and Simon developed a result of great practical as well as theoretical interest: the use of quadratic approximations for all of the components of the cost function implies that the final optimal levels of inventory and production can be stated as linear functions of the past values of production, inventory, and so forth, and of the mean (expected) values of the uncertain future sales. ${ }^{48}$ To the extent that their linear decision rule is an adequate approximation of actual inventory and production decisions, it provides a simple linear specification capable of econometric estimation. One very important application of this method helps firms to cope with seasonal variation in sales; since we use seasonally adjusted data, our estimates abstract completely from this aspect. Also, we are dealing with quarterly data, while many of the detailed decisions on production scheduling refer to weekly or monthly periods.

Without sketching the derivation of the linear decision rules, we will begin with the optimal production rule in order to emphasize the link between the adjustment of production and the adjustment of finished-goods inventories. Let $X_{t}$ be the value of goods whose production is completed in period $t$ ("completions" for short ${ }^{49}$ ) and let $X_{t, t}^{p}$ be the completions planned for period $t$ as of the beginning of that period. The theory of Holt and his associates tells us that $X_{t, t}^{p}$ should be a linear function of lagged values of $X$ and inventories $(I)$ and of expected sales during the current and future periods. The influence of $X_{t-1}$ on $X_{t, t}^{p}$ should be positive because of the costs of changing the level of production, while $I_{t-1}$ should be nega-

48. Planning Production, Inventories, and Work Force.

49. The value of "completions" differs from the value of "production" only because of changes in the value of goods-in-process inventories. We are applying the Holt theory of "production smoothing" to completions when it should more appropriately be applied to "value added" rather than either "completions" or "production." By focusing on completions we separate the modeling of finished-goods inventories from the inventories of goods in process. 
tively related to $X_{t, t}^{p}$ because of the costs of carrying finished-goods inventories. A higher level of expected future sales should induce a higher level of current production. Although we have explicit measures of sales expectations for the current and next quarters $\left(S_{t, t}^{e}\right.$ and $\left.S_{t+1, t}^{e}\right)$, we shall have to assume that expected sales beyond that can be represented as a distributed lag on past new orders: $N O_{t-1}, N O_{t-2}$, and so on..$^{50}$ Therefore

$$
\begin{aligned}
X_{t, t}^{p}= & \beta_{0}+\beta_{1} X_{t-1}+\beta_{2} I_{t-1}+\beta_{3} S_{t, t}^{e}+\beta_{4} S_{t+1, t}^{e} \\
& +\beta_{5} N O_{t-1}+\beta_{6} N O_{t-2}+\beta_{7} N O_{t-3} .
\end{aligned}
$$

Inventories of finished goods are related to completions and sales by the basic identity:

$$
I_{t}=I_{t-1}+X_{t}-S_{t}
$$

It therefore follows that planned inventories are related to planned completions and expected sales according to

$$
I_{t, t}^{p}=I_{t-1}+X_{t, t}^{p}-S_{t, t}^{e} .
$$

Together these equations imply that actual inventories at the end of period $t$ are equal to planned inventories plus unplanned completions minus unanticipated sales:

$$
I_{t}=I_{t, t}^{p}+\left(X_{t}-X_{t, t}^{p}\right)-\left(S_{t}-S_{t, t}^{e}\right) .
$$

The adjustment in production within the quarter will be an increasing function of the unanticipated sales; although more complex adjustment will be considered below, for now we assume proportional production adjustment:

$$
X_{t}-X_{t, t}^{p}=\rho_{1}\left(S_{t}-S_{t, t}^{e}\right) \text {. }
$$

Substituting equations A-3 and A-5 into A-4 yields

$$
I_{t}-I_{t-1}=X_{t, t}^{p}-S_{t, t}^{e}+\left(1-\rho_{1}\right)\left(S_{t, t}^{e}-S_{t}\right) .
$$

Using equation A-1 for $X_{t, t}^{p}$ yields the estimable inventory equation

$$
\begin{aligned}
I_{t}-I_{t-1}= & \beta_{0}+\beta_{1} X_{t-1}+\beta_{2} I_{t-1}+\left(\beta_{3}-1\right) S_{t, t}^{e} \\
& +\beta_{4} S_{t+1, t}^{e}+\beta_{5} N O_{t-1}+\beta_{6} N O_{t-2}+\beta_{7} N O_{t-3} \\
& +\left(1-\rho_{1}\right)\left(S_{t, t}^{e}-S_{t}\right) .
\end{aligned}
$$

Although equation A-7 has been derived from the optimal-decision rule for completions, it may be useful to look at it in a quite different way-as an

50. For firms producing to stock rather than to order, new orders are measured by actual sales. For production-to-order firms, the use of the $N O$ series avoids the problem that arises because the timing of sales and unfilled orders is an endogenous decision of the firm. 
extension of the simpler stock-adjustment model discussed in the text. With this interpretation, equation A-7 implies a more complex determination of optimal inventories; $I_{t}^{*}$ now depends on production smoothing $\left(X_{t-1}\right)$ and on past orders, as well as on very short-run sales expectations. Seen in this way, $\beta_{2}$ still measures the speed of adjustment of actual inventories to their target level and $1-\rho_{1}$ measures the effect of unanticipated sales on endof-period inventories.

Our estimation of equation A-7 and of several extensions of this specification continues to imply a speed of adjustment that is implausibly slow. More specifically, estimation of A-7 yields ${ }^{51}$

$$
\begin{gathered}
\text { (A-8) } I_{t}-I_{t-1}=0.239+0.076 X_{t-1}-0.098 I_{t-1}-0.042 S_{t, t}^{e} \\
(0.198)(0.041) \quad(0.028) \quad(0.019) \\
+0.006 S_{t+1, t}^{e}-0.020 N O_{t-1}-0.001 N O_{t-2} \\
(0.019) \quad(0.017) \quad(0.012) \\
+0.003 N O_{t-3}+0.060\left(S_{t, t}^{e}-S_{t}\right) . \\
(0.007) \quad(0.015) \\
\text { Sample period }=1961: 3-1976: 1 ; \text { standard error }=0.19 ; \\
\text { Durbin-Watson }=1.57 .
\end{gathered}
$$

Note first the now familiar conflict between the apparently slow speed of inventory adjustment $\left(\beta_{2}=0.098\right)$ and the nearly complete elimination of the effect of unanticipated sales $\left(1-\rho_{1}=0.060\right)$. Although the lagged completions variable has the expected positive coefficient, a more careful analysis suggests a further contradiction between the estimated parameters and the underlying theory. The presence of the $X_{t-1}$ variable is sufficient to nullify the expected sales variables; all of them have insignificant coefficients except $S_{t, t}^{e}$, for which the coefficient is negative. As such, the model implies that desired inventories are related primarily to the slowly changing level of production rather than to anticipated sales. Because production is slow to change, even an anticipated increase in sales depresses inventories slightly; that is, $\beta_{3}$ of equation A-1 is less than 1 . Indeed, the similarity of the coefficients of $S_{t, t}^{e}$ and $S_{t, t}^{e}-S_{t}$ indicates that there is no statistically significant (or economically important) difference between anticipated and unanticipated increases in sales.

We have examined several extensions of equation A-8 and have found again and again that the basic parameter estimates are quite robust to alter-

51. The equation is estimated by the instrumental-variable procedure with both $I_{t-1}$ and $X_{t-1}$ excluded from the set of instrumental variables. 
native modifications and that the new variables themselves add little or nothing to the analysis. Consider first the response of production to unanticipated sales-that is, $\rho_{1}$ of equation A-5. The upward adjustment of production to an underestimate of actual sales may not be of the same magnitude as the cut in production in response to an equally large overestimate of actual sales. Moreover, the increase in production may be limited if the average level of capacity utilization was already high. We therefore replace A- 5 by

$$
X_{t}-X_{t, t}^{p}=\left(\rho_{1}+\rho_{2} U P_{t}+\rho_{3} U P_{t} U C A P_{t}\right)\left(S_{t}-S_{t, t}^{e}\right),
$$

where $U P_{t}=1$ if $S_{t} \geq S_{t, t}^{e}$ and $U P_{t}=0$ if $S_{t}<S_{t, t}^{e}$, and where $U C A P_{t}$ is the rate of capacity utilization. Equation A-10 shows that these new variables are themselves insignificant and leave the other coefficients essentially unchanged:

$$
\begin{aligned}
\text { (A-10) } I_{t}-I_{t-1}= & 0.266+0.108 X_{t-1}-0.126 I_{t-1}-0.042 S_{t, t}^{e} \\
& (0.223)(0.046)(0.035) \\
- & 0.002 S_{t+1, t}^{e}-0.032 N O_{t-1}-0.006 N O_{t-2} \\
& (0.021) \quad(0.020) \\
- & 0.004 N O_{t-3}+0.084\left(S_{t, t}^{e}-S_{t}\right) \\
& (0.009) \quad(0.025) \\
& -0.142 U P_{t}\left(S_{t, t}^{e}-S_{t}\right) \\
& (0.220) \\
+ & 0.128 U P_{t}\left(U C A P_{t}\right)\left(S_{t, t}^{e}-S_{t}\right) . \\
& (0.257)
\end{aligned}
$$

Sample period $=1961: 3-1976: 1 ;$ standard error $=0.22$; Durbin-Watson $=1.64$.

The original theory of Holt and his associates also dealt with optimal employment and layoff policies. As such, a more complete specification of the optimal-production equation would add lagged unemployment and employment variables to the basic specification of equation A-1. Having a large number of workers on layoff imposes a cost on durable-goods manufacturing firms (the unemployment-insurance tax and the risk of losing experienced workers) that should provide an incentive for greater production and inventory accumulation. The number of workers on layoff $\left(L_{t-1}\right)$ can be converted to an equivalent volume of output by multiplying that number by the corresponding ratio of output per employee $\left(X_{t-1} / E_{t-1}\right)$. The resulting variable may also be written $\left(L_{t-1} / E_{t-1}\right) X_{t-1}$. Although the required 
time series on $L_{t} / E_{t}$ is not available, the very closely related series of unemployment rates for workers previously engaged in durable-goods manufacturing - that is, $R U M D_{t}=L_{t} /\left(L_{t}+E_{t}\right)$-is available. We therefore include $R U M D_{t-1} X_{t-1}$ to represent the effect of the number of workers on layoff measured in terms of equivalent production.

A second employment effect that in principle should be taken into account is the availability of experienced employees in the labor force as a whole, including those currently employed. A firm can more readily expand production if workers with relevant experience can be found, even if they have to be hired away from other firms. To measure this availability we use the lagged value of the ratio of the maximum number of persons ever employed in durables manufacturing to the number currently employed, $E_{t-1}^{\max } / E_{t-1 .}{ }^{52}$ Again we convert this to an equivalent output value by multiplying the ratio by $X_{t-1}$.

Equation A-11 shows that only the employment variable is significant, but the sign of its coefficient is contrary to the theoretical prediction. The coefficients of the other variables are essentially unaffected but the greater collinearity among the variables raises substantially the standard errors of the lagged inventory and production coefficients:

$$
\begin{aligned}
\text { (A-11) } I_{t}-I_{t-1}= & 0.822+0.016 X_{t-1}-0.043 I_{t-1}-0.045 S_{t, t}^{e} \\
& (0.437)(0.059)(0.087) \quad(0.016) \\
& +0.015 S_{t+1, t}^{e}-0.009 N O_{t-1}-0.008 N O_{t-2} \\
& (0.018) \quad(0.021) \\
& +0.005 N O_{t-3}+0.059\left(S_{t, t}^{e}-S_{t}\right) \\
& (0.008) \quad(0.014) \\
& -0.0008 R U M D_{t-1} X_{t-1}+0.026 \frac{E_{t-1}^{\max }}{E_{t-1}} X_{t-1} .
\end{aligned}
$$

$$
\begin{gathered}
\text { Sample period }=1961: 3-1976: 1 ; \text { standard error }=0.17 \text {; } \\
\text { Durbin-Watson }=1.57 \text {. }
\end{gathered}
$$

The linearity of the decision rules and the "certainty equivalence" property ${ }^{53}$ of the analysis by Holt and his associates depend on the restriction that any uncertain quantities enter the analysis in an additive way. This rules out the possibility of considering uncertain future prices as well as uncertain future sales and still getting the very attractive results of the form they derived. More generally, their model cannot be used to analyze the

52. It is clear that the underlying notion is less valid at the aggregate level of durables manufacturing than at the more detailed industry or even firm level.

53. That is, the property that uncertain variables can be replaced by their mean values. 
effect of changes in interest rates or other costs of carrying inventories. These restrictions are unfortunate because much macroeconomic interest attaches to the question of whether changes in interest rates or inflation affect inventory holdings. Previous studies generally have found no such effect but they have been seriously marred by one or both of two major shortcomings.

First, it has been common to consider the effect of either inflation or of the rate of interest but not to include both at the same time. Since these variables would be expected to move together but to have coefficients of opposite sign, the omission of either will tend to bias the coefficient of the included variable toward zero. ${ }^{54}$

Second, researchers have usually included the rate of inflation (or the rate of interest) in the equation without any adjustment for the scale of output or inventories. We began our research on this aspect of inventory behavior with the expectation that including both anticipated inflation and the rate of interest and scaling them by the level of completions would yield plausible and statistically significant coefficients. Once again our expectations were frustrated by the data. We tried several alternative specifications, including different ways of measuring inflation and different scaling variables. In all of the specifications, the coefficient of the price-inflation variable was always small and statistically insignificant. This may indicate a lack of sensitivity of inventory demand to expected inflation, but a number of other explanations are possible. It may reflect our inability to measure price expectations in an appropriate way. Alternatively, prices may rise when particularly strong demand reduces inventories or prevents them from growing at the rate that firms would prefer; this problem of simultaneity can occur in both competitive and oligopolistic, price-setting industries.

The interest-rate variable is not affected as much by these two problems, although we do not wish to minimize the difficulty of choosing an interestrate variable, the existence of credit rationing, and the simultaneous effect of inventory-loan demand on the relevant interest rate. The coefficient of the interest-rate variable is generally statistically insignificant and implies a long-run elasticity of inventories with respect to the interest rate of only about -0.10 .

These results are illustrated by equation A-12. Here firms are assumed to

54. See Martin S. Feldstein, "Inflation, Specification Bias, and the Impact of Interest Rates," Journal of Political Economy, vol. 78 (November/December 1970), pp. 1325-39. 
predict naively the one-quarter rate of increase for finished-goods prices $\left(\pi_{t+1}^{e}=\pi_{t}\right)$, and the rate of interest is measured by the prevailing rate on commercial paper $\left(i_{t}\right)$. These variables are scaled by the lagged value of completions.

$$
\begin{gathered}
\text { (A-12) } I_{t}-I_{t-1}= \\
0.034+0.062 X_{t-1}-0.083 I_{t-1}+0.003 S_{t+1, t}^{e} \\
(0.289)(0.034) \quad(0.029) \quad(0.018) \\
-0.042 S_{t, t}^{e}-0.009 N O_{t-1}+0.002 N O_{t-2} \\
(0.018)(0.017) \quad(0.011) \\
+0.002 N O_{t-3}+0.062\left(S_{t, t}^{e}-S_{t}\right) \\
(0.007) \quad(0.014) \\
-0.00006 \pi_{t} X_{t-1}-0.0003 i_{t} X_{t-1 .} \\
(0.00009) \quad(0.0004) \\
\text { Sample period }=1961: 3-1976: 1 ; \text { standard error }=0.19 ; \\
\text { Durbin-Watson }=1.58 .
\end{gathered}
$$

The inflation and interest-rate variables are insignificant both statistically and economically. Similar results obtain with different measures of both price expectations and interest costs.

Further modifications of the basic equation do not alter the conclusion about the apparently slow speed of stock adjustment. Moreover, at least with quarterly observations of seasonally adjusted data, the equations implied by the model of Holt and his associates do not provide a better explanation of inventory investment than either the traditional stockadjustment model or the target-adjustment model.

In concluding this discussion, we emphasize that our work should not be viewed as a criticism of the optimal-production and industry theory of Holt and his associates. The principal purpose of that theory is to aid businessmen to make decisions. To the extent that the advice had not been widely adopted during at least most of the sample period, the theory may be useful managerial economics but a poor prediction of actual practice. In addition, much of the potential usefulness of the methods-and, we suspect, many of its actual applications-lies in dealing with seasonal variations that are explicitly ignored here. Furthermore, the timing of inventory adjustment within the quarterly period may well be guided by these principles of optimal production. This possibility can be explored only with monthly data. 


\section{APPENDIX B \\ Inventory Measurement: Conversion from Book Value}

THE DATA used in this study are from "Manufacturers' Shipments, Inventories and Orders," M3-1, a bulletin published monthly by the U.S. Bureau of the Census, and periodic updates published by the Department of Commerce. Inventories for durables manufacturing are listed from 1953:1 to the present, measured in book value and seasonally adjusted. Shipments, new orders, and unfilled orders are available to the present, adjusted both seasonally and for trading days.

Because of the difficulty of valuing inventories of materials and work in process, it was decided to adjust the finished-goods inventory figures and then subtract them from the total adjusted figure reported in the national income accounts (NIA) to obtain a residual series for the former two stages of fabrication. ${ }^{55}$ The method used to inflate and adjust finished-goods inventories is similar to that used by Stanback and by Herman and her associates. ${ }^{56}$

Firms may use one or more of several accounting methods for inventory valuation. The two most prominent are first-in-first-out (FIFO) and lastin-first-out (LIFO), which was first allowed for tax purposes in 1939 and has grown in popularity in recent years because it prevents the appearance of illusory, inflation-induced "inventory profits." Following previous work, we assumed all inventories to be either FIFO or LIFO. In addition, the LIFO percentage throughout the sample period (1953:1 to 1976:1) was

55. Since NIA values are based on unpublished raw inventory data, which have been benchmarked up to the 1972 Census and the 1973 Annual Survey of Manufactures, this procedure may impart a small upward bias to the residual series. Because of the nature of the benchmarking technique, there should be no serious bias in quarterly changes in this series.

56. Stanback, Postwar Cycles; Herman and others, "Manufacturing and Trade Inventories and Sales." 
taken to be 20 percent. ${ }^{57}$ Book-value inventories were then separated into the two categories, adjusted separately, and then added together again.

\section{FIFO Conversion}

The more rapid the turnover of inventory, the more closely FIFO book value corresponds to current-dollar market value. Since both prices and inventories are measured monthly, an inventory with a one-month turnover time will be FIFO-valued at current prices. Normally, however, turnover time in durables manufacturing tends to be longer than one month. Further, it will rise and fall with the level of sales and production.

In adjusting FIFO inventories, we follow two conventional procedures: assuming a constant turnover time (in this case five months) and a uniform age distribution (over the previous five months). If $Z(t)$ is the amount, at time $t$, that is assumed to have been completed at every instant over the past five-month period, and $P$ is the price, then

$$
\int_{\tau=0}^{5} Z(t) P(t-\tau) d \tau=I(t)
$$

or

$$
Z(t)=\frac{I(t)}{\int_{\tau=0}^{5} P(t-\tau) d \tau} .
$$

The total real inventory value is then

$$
\int_{\tau=0}^{5} Z(t) d \tau=\frac{I(t) \int_{\tau=0}^{5} d \tau}{\int_{\tau=0}^{5} P(t-\tau) d \tau}=\frac{I(t)}{\frac{1}{5} \int_{\tau=0}^{5} P(t-\tau) d \tau}
$$

We approximate

$$
\int_{\tau=0}^{5} P(t-\tau) d \tau
$$

by $P(t)+P(t-1)+P(t-2)+P(t-3)+P(t-4)$, obtaining

$$
I_{(t)}^{\text {real }}=\frac{I(t)}{\bar{P}(t)},
$$

57. It would, of course, be preferable to use a different LIFO percentage for each quarter, were such a series available. Herman and her associates did this for the period beginning July 1974, using the fixed-percentage method before that date. 
where $\bar{P}(t)$ is the simple mean of prices in the current and last four periods. (In all deflations the wholesale price index for durables manufacturing, $1972=100$, was used.)

After monthly stocks were calculated, as described above, quarterly values were extracted to make a quarterly FIFO inventory series for finished goods.

\section{LIFO Conversion}

In periods during which LIFO inventories increase, the change is valued in current prices; that is, deflating the increase by the current price level will yield the real inventory increase. When decumulation occurs, this is not true. Inventories that are run down were accumulated in previous periods. It is easiest to consider a LIFO inventory as a series of layers: an increase adds layers to the top; a decrease removes layers from the top. Thus, during a period of sustained decumulation, inventories being used up will be valued at prices that may be quite low compared with current prices.

An algorithm was used to convert monthly book-value changes into realdollar changes. Monthly changes were then summed to get quarterly changes. One further problem remained: the initial valuation of the LIFO stock. The value was set as if it were a FIFO stock-that is, the deflator was the mean price over five periods. Whatever error this practice introduces into the measurement of inventory stocks, it obviously does not affect subsequent measurement of inventory investment or any regression coefficient.

LIFO inventories from 1953:1 to the present were estimated and added to the previously calculated FIFO inventories to get total finished-goods inventories for durables manufacturing in 1972 dollars. This series was then subtracted from NIA values for total inventories in durables manufacturing to obtain, for the period 1958:4 to the present, the residual series described above. 


\section{Comments and Discussion}

Robert E. Hall: This paper does two things: it completely demolishes existing econometric models of inventory fluctuations, and it attempts to create a new model based on an entirely different principle. I judge the paper a total success in the first respect but am more skeptical about the second. As a whole, it makes a major contribution, all the more impressive because it is the first venture of the authors into this difficult field of research.

The demolition of the existing models of inventory fluctuations proceeds at two levels, but the basic point is the same. Almost all existing models explain inventory fluctuations as the lagged response to mistakes in expectations about sales. The lag from the mistakes to their correction turns out to be extremely long, especially in equations based on the full postwar period. Feldstein and Auerbach argue first in commonsense terms that it is simply implausible that businesses wait so long to make what turn out to be minute corrections in the level of production. They buttress this point by reestimating a traditional inventory equation and pointing to two major findings: (i) the speed of adjustment (their $\lambda$ ) is extremely small, around 0.06 with a standard error of 0.02 , and (ii) the fraction of sales errors that are not corrected within the quarter (their $\delta$ ) is also extremely small, around 0.04 with a standard error of 0.01 . They note that the standard theory implies that $\delta$ should be $1-\lambda$ if the adjustment process is taken seriously: it doesn't make sense within the theory for part of the expectation errors to be corrected immediately and a small remainder to take years to correct. They miss the opportunity to clinch the point with a formal statistical test of the hypothesis $\delta=1-\lambda$. Using the covariance supplied to me by the authors, I have computed the relevant $t$-statistic, and it turns out to be 45 ! As far as I know, this is the largest $t$-statistic for an interesting hypothesis ever to appear in the Brookings papers. To my mind, nothing survives of the received theory after this demolition. 
Feldstein and Auerbach then turn to a theory of their own. They believe that expectation errors have almost nothing to do with fluctuations in inventories; this explains the very low estimates of $\delta$ in all of their equations. Sales-expectation errors can be made up by tiny adjustments in production within the quarter and will never contribute much to quarterly fluctuations. Low values of the adjustment speed $\lambda$ are to be explained by sluggish movement in the target level of inventories. The new theory fits the data somewhat more comfortably, but the extreme sluggishness remains a puzzle. The authors allude to investments in warehouses and the like as an inhibition to movements, but their estimates of the adjustment speeds of inventories are actually lower than many estimates of adjustment speeds for fixed capital. Further, the new theory has a central testable implication: the long distributed lag that describes the inventory-adjustment process should not apply to sales-expectation errors. In their model, this means that the coefficient of the lagged expectation error should be $-(1-\mu)$ times the coefficient of the current expectation error. Their attempts to test this hypothesis have given rise to an econometric controversy that remains unsettled, but even the most favorable test (the one reported in the paper) casts serious doubt on the hypothesis. The $\chi^{2}$-statistic of 2.59 corresponds to a $t$-statistic of 1.6, which would be observed only one time in ten if the null hypothesis were true. Borderline acceptance of the null hypothesis should not be interpreted in its favor. Further, the test is not a mere technicality: the heart of the proposed model is exactly that the sluggish adjustment process does not apply to errors in expectations. I remain skeptical about the empirical support for the new theory.

Perhaps the most important weakness of the paper is its exclusive reliance on a sales-expectations variable whose shortcomings are amply documented at the beginning of the paper. The paper could have made its essential point without using this defective variable if it had made one of the weakest assumptions of rational expectations - that expectations errors are serially uncorrelated. Then the extremely high serial correlation of inventory levels could have been cited as evidence that expectation errors have almost nothing to do with inventory fluctuations. The logical structure of this argument would have been the same as my discussion of the role of expectations errors in the movements of unemployment (BPEA, 2:1975). There is no question that this alternative approach would further support the basic point of the paper. 
Michael C. Lovell: The most surprising thing about the Feldstein and Auerbach contribution is that the flexible accelerator, with a new twist, does better on the new sample period than we had any right to expect. The new sample period, 1961:3 through 1976:1, has been characterized by dramatic price movements, by a credit crunch, and by the worst recession since World War II. However uncomfortable the last decade has been, Nature has done a nice job of rocking the economy in an experimental design that is particularly interesting for econometricians investigating the determinants of inventory investment. The experience looks like a classic Hawtrey-Keynes inventory cycle. Yet Feldstein and Auerbach find that inventory investment can be explained by the old standbys-sales volume, orders, and the lagged inventory stock. Their empirical results suggest that inventories are insulated from both credit crunch and inflation!

Feldstein and Auerbach are to be commended for undertaking the tedious work of deflating durable goods by stage of fabrication. This was essential, given the sizable price movements of the last decade. Certain data problems remain, however. First, the authors have not duplicated the Commerce Department's deflation procedure in full detail. They deflate the aggregate for finished durable goods rather than the two-digit industry components. Further, they assume that 20 percent of inventories are on LIFO accounting and 80 percent on FIFO throughout the period; since July 1974, Commerce has carefully monitored the changing LIFO-FIFO proportion in order to allow for new adoptions of LIFO, which are in good measure induced by inflation. Since Feldstein and Auerbach obtain series on purchased materials and goods in process by subtracting their deflated series on finished goods from Commerce-deflated total stocks, the discrepancies in procedures may be compounded.

A second data problem arises from the markup factor, an important complication that I myself overlooked in some of my earlier work. Accountants are conservative, evaluating inventory at cost or market, whichever is the lowest. An item in finished-goods inventory is generally evaluated at a lower figure than it customarily sells for. Because Feldstein and Auerbach neglect this distinction, they are in trouble whenever they estimate output by subtracting the change in finished-goods inventory from sales. Also, the first of their characterizations of inventory movements-that changes in finished-goods inventory are small relative to output-is exaggerated because only the numerator of this ratio contains the markup. 
A third data problem involves the double counting of sales, which is particularly serious for the aggregation of durable goods. Steel and rubber sales are counted twice, once when they are sold to General Motors and again when G.M. sells the car. This influences inventory-to-sales ratios throughout the paper.

I am not convinced that these factors seriously influence the regression results reported in the paper. Obviously, it would be exceedingly useful, since we now know that the business cycle is not obsolete, if the Commerce Department had the resources to deflate at the two-digit industry level by stage of fabrication. ${ }^{1}$ It would also be helpful to know more about unfilled orders and their deflation: how hard a price and delivery commitment do they represent?

The empirical results suggesting that inventories are insulated from credit crunch and inflation are consistent with those of most earlier studies. My own empirical work over the years suggests that the probability of obtaining an interest-rate coefficient with negative sign is 50 percent. With regard to price hedging, I concluded that manufacturers do not successfully speculate or "price hedge," although conceivably they tilt the composition of their stocks in an attempt to take advantage of rising prices of certain inputs. ${ }^{2}$ Paul Kuznets found the strongest evidence in support of the proposition that credit conditions influence inventory behavior. ${ }^{3}$ My feeling is that credit conditions and inflation are more likely to influence purchasedmaterials stocks than finished-goods inventory; perhaps Feldstein and Auerbach would have found more if they had scaled the interest-rate and sales variables with stocks rather than output, which would amount to incorporating capital gains and carrying costs.

I think there is a reason why price changes and interest rates do not show

1. An indication that details of deflation may not make all that much difference is provided by some results of Paul W. Kuznets, who found that essentially the same estimates were obtained with current as with Commerce-deflated data over the period 1947-61. In particular, he estimated the adjustment coefficient, $\lambda$ in Feldstein-Auerbach's notation, at 0.280 with deflated data and 0.288 with undeflated data; however, the internal-finance variable was influenced. See his "Financial Determinants of Manufacturing Inventory Behavior" (Ph.D. dissertation, Yale University, 1964), pp. 103-07.

2. Michael Lovell, "Manufacturers' Inventories, Sales Expectations, and the Acceleration Principle," Econometrica, vol. 29 (July 1961), pp. 293-314.

3. Paul W. Kuznets, "Financial Determinants of Manufacturing Inventory Behavior: A Quarterly Study Based on United States Estimates, 1947-1961," Yale Economic Essays, vol. 4 (Fall 1964), pp. 331-69. 
up. Revising inventory rules in order to reflect changes in carrying costs is a tedious business. The linear decision rules developed by Holt and his associates provide a simple rule for adjusting to changes in anticipated sales; but the rules have to be reworked if changes in carrying costs are to be taken into account. And Thomson Whitin's square-root rule has to be rescaled if a firm wishes to adapt to changes in carrying costs. When interest costs are generally low and fluctuations are minor, managers may conclude that calling back their consultants is not worth it. In the last decade, it surely must have been worthwhile, but the adjustment lag for changes in credit conditions may be much more tedious and convoluted than Feldstein and Auerbach allow in their regressions. But, also, in the past few years, firms have been very slow in adjusting to LIFO accounting, which has sizable tax benefits; why should they be more active in adjusting stocks to changes in credit cost and inflation?

On the matter of adjustment lags, the fundamental conclusion of Moses Abramovitz was that the simple accelerator cannot explain the timing of inventory movements over the cycle. Metzler had emphasized the role of forecast errors in explaining the inventory cycle, but a number of empirical studies demonstrate that this factor does not explain the cyclical timing of inventories. Rather, inertia is the crucial factor, and it seems if anything to be more important for Feldstein and Auerbach than for previous investigators.

Feldstein and Auerbach are inaccurate in reporting that "previous investigators have interpreted their parameter estimates as implying that the gap between actual and desired inventories is reduced by only about 10 percent per quarter." When I initially studied inventories, lagged stocks appeared in the equation for inventories of durable finished goods with a coefficient of 0.1829 ; the coefficient is 0.3628 for stocks of purchased materials and goods in process. ${ }^{4}$

I rationalized this slow adjustment toward equilibrium by arguing that it was not unreasonable relative to a range for the speed of adjustment of 0.28 to 0.46 reported by Bronfenbrenner and Mayer in their study of money balances. ${ }^{5}$ I suggested that adjustment of inventories might involve capital expenditure for warehouse space. And I appealed to Samuelson's

4. Lovell, "Manufacturers' Inventories," pp. 300-01.

5. Martin Bronfenbrenner and Thomas Mayer, "Liquidity Functions in the American Economy," Econometrica, vol. 28 (October 1960), p. 817. 
"Correspondence Principle," arguing that within the context of my multisector model, faster adjustment would contribute to economic instability. ${ }^{6}$

Subsequent research based on better data disclosed that firms correct promptly for errors in sales expectations but plan only small adjustments in stocks in response to changes in anticipated sales. Using data for aggregate durable goods, Hirsch and I found that firms plan a 0.332 adjustment toward equilibrium within the quarter. ${ }^{7}$ We also studied data for eightythree individual firms and found that small firms are less subject to inertia in adjusting their finished-goods inventories. Larger firms are inflexible, but they have an advantage in adjusting stocks of purchased materials and goods in process, perhaps because they have more clout with suppliers. But while the inertia factor does not seem as strong as Feldstein and Auerbach suggest, it is still strong enough to cause discomfort. The careful theoretical analysis by Carlson and Wehrs concludes that while such slow adjustment is not incompatible with profit maximization, it can be rationalized only for extreme values of the cost function's parameters. ${ }^{8}$

The target-adjustment model is an interesting contribution. However, it does not receive decisive empirical support. Comparison of regressions 14 and 15 with regressions 7 and 8 reveals that the additional term does not materially influence the standard errors; indeed, regression 15 shows that the complicating term introduced by their analysis has a $t$-ratio of only two-thirds.

Feldstein and Auerbach assume in formulating their model that firms adjust immediately to target - that the inertia coefficient $(\delta)$ equals unity. I think they might have done better if they had estimated $\delta$. I would generalize their equation 9 to read

$$
I_{t}=\delta I_{t}^{*}+(1-\delta) I_{t-1}+\gamma\left(S_{t, t}^{e}-S_{t}\right) .
$$

Substitution eventually yields, with equation 10 ,

$$
\begin{gathered}
I_{t}=[(1-\delta)+(1-\mu)] I_{t-1}+\delta \mu \gamma S_{t, t}^{e}-(1-\delta)(1-\mu) I_{t-2} \\
+\gamma\left(S_{t, t}^{e}-S_{t}\right)-(1-\mu) \gamma\left(S_{t-1, t-1}^{e}-S_{t-1}\right)
\end{gathered}
$$

6. Michael C. Lovell, "Buffer Stocks, Sales Expectations, and Stability: A MultiSector Analysis of the Inventory Cycle," Econometrica, vol. 30 (April 1962), pp. 267-96.

7. Albert A. Hirsch and Michael C. Lovell, Sales Anticipations and Inventory Behavior (Wiley, 1969), p. 225.

8. John E. Carlson and William E. Wehrs, "Aggregate Inventory Behavior: A Critical Study of a Class of Models," in George Horwich and Paul A. Samuelson, eds., Trade, Stability, and Macroeconomics: Essays in Honor of Lloyd A. Metzler (Academic Press, 1974). 
an expression that differs from theirs in that it includes stocks lagged two periods, unless either $\delta$ or $\mu$ is unity. Perhaps this additional variable would help them empirically.

I am not quite convinced that their target-adjustment model is the right approach. For one thing, I believe they exaggerate the distinction between their model and those in earlier studies. In talking about "undesired" or "surplus" inventories, no one means that the firm is not making the best of the stocks it inherited at the beginning of the current period; they could always be liquidated by a sufficient reduction in prices. Rather, keeping "surplus" stocks is profitable as a means of short-run maximizing; and longer-run adjustment leads to their liquidation. The Feldstein-Auerbach target stock eventually adjusts to the same equilibrium stock, so semantic differences aside, we all end up at the same place. In any event, I think a more attractive approach may be to have equilibrium stocks depend upon "normal sales," an unobserved variable to be distinguished from $S_{t, t}^{e}$. Suppose that normal sales, $S^{n}$, are generated by Nerlove's adaptive-expectations model,

$$
S_{t}^{n}=\psi S_{t-1}^{n}+(1-\psi) S_{t}^{e} ;
$$

that desired inventory is linearly related to normal sales,

$$
I_{t}^{d}=\beta_{0}+\beta_{1} S_{t}^{n} ;
$$

and that actual inventory is again determined by equation $9^{*}$. Proceeding as before, the result is

$$
\begin{aligned}
I_{t} & =(1-\psi) \delta \beta_{0}+\delta \beta_{1}(1-\psi) S_{t, t}^{e}+(1-\delta+\gamma) I_{t-1} \\
& -\psi(1-\delta) I_{t-2}+\gamma\left(S_{t}^{e}-S_{t}\right)-\psi \gamma\left(S_{t-1 . t-1}^{e}-S_{t-1}\right) .
\end{aligned}
$$

The interesting thing is that this is identical in form to equation $13^{*}$ above, but I myself find the "normal sales" notion appealing; it relates to the approach used by Zellner and his associates in their study of the consumption function. ${ }^{9}$ We must wait and see what happens when Feldstein and Auerbach add $I_{t-2}$ to their regression.

Feldstein and Auerbach emphasize the imprecision of sales expectations. However, regression 1 of their paper indicates there is net forecasting value over and above the seasonal. Since the expectations series is derived from a smaller sample than their sales series, part of the apparent inaccuracy

9. A. Zellner, D. S. Huang, and L. C. Chau, "Further Analysis of the Short-Run Consumption Function with Emphasis on the Role of Liquid Assets," Econometrica, vol. 33 (July 1965), pp. 571-81. 
may arise from sampling error. In any event, the authors' analysis suggests that entrepreneurs are much more accurate than had been suggested by the notorious railroad shippers' forecasts analyzed by Ferber, Modigliani and Sauerlender, and Hart. ${ }^{10} \mathrm{I}$ think that the results reported by Feldstein and Auerbach are roughly comparable with what Hirsch and I found in analyzing data for both individual firms and the aggregate. However, it would be interesting to try and partition the error into its inflation and real components.

The slope of 0.553 in regressing actual on anticipated sales, equation 1 of their paper, does not indicate that predictions are subject to a systematic positive or negative bias. The slope is less than unity because the prediction error is correlated with the forecast sales change. Jack Muth advised me years ago that the way to test his rational-expectations concept is to regress the realized on the forecast change. He predicted that the slope would be unity, and that other variables containing information available at the time the forecast is made, such as lagged sales, must enter with zero coefficients. The Feldstein-Auerbach regression implies that sales expectations are not rational. They must join Hirsch and Lovell in this heresy. ${ }^{11}$ Firms do not report forecasts appropriate for use as certainty equivalents in linear decision rules; they do not succeed in taking optimal advantage of all the information available at the time they make their forecasts.

The detailed discussion of stocks of purchased materials and of goods in process is commendable. The regression that Feldstein and Auerbach end up with, equation 35 , looks very similar to the durables-manufacturing equations I estimate over the 1948-55 sample period with Tom Stanback's data. ${ }^{12}$ However, in subsequent work I found it useful to look separately

10. Robert Ferber, The Railroad Shippers' Forecasts (University of Illinois, 1953); Franco Modigliani and Owen H. Sauerlender, "Economic Expectations and Plans of Firms in Relation to Short-Term Forecasting," in National Bureau of Economic Research, Conference on Research in Income and Wealth, Short-Term Economic Forecasting (Princeton University Press for the National Bureau of Economic Research, 1955); Albert G. Hart, "Quantitative Evidence for the Interwar Period on the Course of Business Expectations: A Revaluation of the Railroad Shippers' Forecast," in The Quality and Economic Significance of Anticipations Data, A Conference of the UniversitiesNational Bureau Committee for Economic Research (Princeton University Press for the National Bureau of Economic Research, 1960).

11. Hirsch and Lovell, Sales Anticipations, p. 178, report a slope of 1.07 for the durables aggregate, but this broke down for a number of component industries and for individual firms.

12. Lovell, “Manufacturers' Inventories,” p. 300. 
at defense orders, obligations, and progress payments. I do not know whether data on defense-procurement obligations would be as fruitful for the Vietnam buildup as they were for the Korean mobilization. I also think that Feldstein and Auerbach are to be commended for the link they establish between workers on layoff and inventories. ${ }^{13}$

To conclude, I am delighted that Feldstein and Auerbach have not only provided us with a fine paper, but also have promised to continue their exploration, looking at more detailed data partitioned by stage of fabrication. I would offer one additional word of counsel. At several points they emphasize the usefulness of linear decision rules derived from quadratic cost functions; I also like to cite Holt and his associates in indicating that my model is compatible with the assumption of profit maximization using their linear decision rules. However, I have come to suspect that, while the hypothesis of maximization will go a long way, the deviations from profit maximization may be very important. I have already mentioned the Hirsch-Lovell heresy with regard to the assumption of rational expectations. As another heresy, there is at least some evidence that the division of managerial labor may cause a lack of consensus within the firm. The Commerce Department survey has revealed that firms' responses are biased toward reporting inventories as "excessive."14 Murray Foss argues that the person in the treasurer's office who fills out the form may be concerned primarily with the carrying cost of inventories rather than their convenience yield; in contrast, purchasing agents may be under pressure from production schedulers to maintain ample reserves of production materials. Hirsch and Lovell also suggested that in setting their output targets, firms do not give much attention to production-smoothing considerations, and as a result, actual output deviates from the planned level because of difficulties encountered in abrupt changes. It will be interesting to see whether subsequent work on the new data will support our observations.

13. Their approach is to be distinguished from that of Schram, who considered, within the context of a simultaneous-equation model, the interactions among the stock of physical capital, employment, and liquid capital (including inventory); see R. Schram, "The Influence of Relative Prices, Production Conditions and Adjustment Costs on Investment Behaviour," Review of Economic Studies, vol. 37 (July 1970), pp. 361-76.

14. Murray F. Foss, "Manufacturers' Inventory and Sales Anticipations: A New Survey," in American Statistical Association, Proceedings of the Business and Economic Statistics Section, 1961 (ASA, n.d.), pp. 234-51. 


\section{General Discussion}

Charles Holt said that recent developments - the widespread adoption of the computer for inventory-control purposes and recent business-cycle behavior-made it timely to reexamine inventory dynamics, and he commended the authors for having done this. He did express some concern, however, that the level of aggregation at which the inquiry had been conducted might have obscured some of the underlying dynamics at the firm or industry level. He noted that the materials inventory of one firm is the finished-goods inventory of another and pointed to the difficulties of identifying "finished goods" precisely. Other panel members elaborated on the aggregation issue: Martin Baily argued that aggregation might obscure the costs faced by individual firms. Changes in output mix, even within a single firm, might entail costly readjustments even though the aggregate level of inventories was unchanged. Arthur Okun argued that if there was a wide variation among firms in the technologically determined ratio of inventories to sales, shifts in the distribution of output between firms with high inventory-sales ratios and firms with low ones would bias the measured speed of adjustment. William Poole suspected that the use of aggregated forecasts might have led to the poor performance of the expectations variable; however, Michael Lovell reported that he had found aggregated expectations more accurate than those of individual firms. Feldstein agreed that further work was required at a more diaggregated level, but he felt that the proposition that inventory changes are small in relation to production levels would emerge as generally applicable.

Several participants expressed concern over the poor quality of the expectations data. George Perry questioned what use it was to infer adjustment speeds and other structural characteristics of the inventory decision process from sales-expectations data that were demonstrably so poor. If, in fact, manufacturing firms have a much better view of their prospective shipments and sales than the expectations data show, the correct coefficient on "true" sales surprises might be much larger than the estimated one, even for a period as short as a quarter. Okun expanded on this point, noting that a better estimate of true sales surprises might solve the asymmetry puzzle - the estimated greater response of production schedules to sales surprises than to excess inventories. By way of explaining the poor predictive performance of the sales-expectations data, Okun noted that firms might adjust their expectations internally to changing market conditions 
but continue to report routinely to the government survey on the basis of sales expectations that were previously formulated: the people who fill out the forms are not the ones who run the plant. Holt, on the other hand, suggested that crude seasonal adjustments by firms-which often rely simply on comparisons with the previous year-would introduce a sixmonth lag in sales expectations, even if they were properly reported.

Feldstein expressed interest in Hall's suggestion, in his formal discussion, of proceeding on a minimal rational-expectations assumption as a test of the theory that did not require expectations data, particularly for more disaggregated studies in which detailed expectational data are not available. He stressed his belief that firms would not be concerned about their poor sales expectations because of the small size of inventory adjustment. Stephen Marston, however, expressed concern about ignoring the costs of adjustment, especially when firms underpredicted sales; and Michael Wiseman noted that this would apply particularly to periods of high capacity utilization.

Paul Samuelson asked if one might distinguish between the competing theories on the basis of the way in which they had explained the 1974-75 experience, which surprised most model forecasters, first by the persistence of the accumulation and then by the magnitude and suddenness of the swing to liquidation. Marston doubted that the theories could be distinguished, as they implied almost identical explanatory variables. Stephen Goldfeld observed that the high degree of serial autocorrelation in the error terms gave him little confidence in the value of hypothesis testing on the basis of these equations. Others advanced reasons for the apparent success of the Feldstein-Auerbach equations in explaining 1974-75 fluctuations in manufacturing inventories. Okun stressed the atypically small role that liquidation of durable-goods inventories had played in the 1974-75 inventory swing and speculated that much of the inventory fluctuation had been passed forward to the durables-trade sector, so that this was where the peculiar behavior took place. George Jaszi believed that the atypical behavior was in fact in the nondurables sector, primarily in food and oil. He also reasoned that the data on durables should, at a minimum, remove auto sales and orders since, in this industry, the two coincided and did not bear the same relationship as they did in other durable-goods industries. Perry noted that most of the peculiarities in durable goods in 1974-75 showed up in sales and orders, which the Feldstein-Auerbach equations took as given. 
In response, Feldstein said that he had been reassured, and somewhat surprised, by how well the equations had performed. He had expected that omitted variables, designed to capture fears of shortages and expectations of further price rises, might well have been required for a better explanation, but this had not been the case. He emphasized, however, that the aim of the paper was not to specify a new equation for predicting inventory changes, but rather to provide a better rationale for the estimated coefficients that appear in the old equations than that given by the stock-adjustment story. Feldstein acknowledged that further research might well establish whether other variables should be added. He commented that Lovell's description of a model that had different speeds of adjustment for inventory targets and for expectations corresponded to the "two-speed target-stock adjustment model" referred to in the paper and noted that estimation of such a model was already under way. 